\title{
Intergenerational Disagreement and Optimal Taxation of Parental Transfers*
}

\author{
Nicola Pavoni ${ }^{\dagger}$ and Hakki Yazici ${ }^{\ddagger}$ \\ Preliminary Version
}

January 31, 2015

\begin{abstract}
We study optimal taxation of bequests and inter vivos transfers in a model where altruistic parents and their offspring disagree on intertemporal trade-offs. We show that laissez-faire equilibrium is Pareto inefficient, and whenever offspring are impatient from their parents' perspective, optimal policy involves a positive tax on parental transfers. Cautioned by the technical complications present in this class of models, our normative prescriptions do not rely on the assumption of differentiability of the agents' policy functions.
\end{abstract}

JEL classification: E21, H21, D03, D91.

Keywords: Parental transfer taxation, intergenerational disagreement, altruism.

*We thank Michelle Tertilt, four anonymous referees, Per Krusell, Marco Ottaviani, Vincenzo Quadrini, seminar participants at Bogazici University, Goethe University in Frankfurt, IIES, the SED meetings in Ghent, University of Alicante, University of Bologna, University of Oxford, and the 8th CSEF-IGIER Symposium on Economics and Institutions for their comments and suggestions. Pavoni gratefully acknowledges financial support from the European Research Council, Starting Grant \#210908. Yazici gratefully acknowledges financial support from the European Community Framework Programme through the Marie Curie International Reintegration Grant \#268457.

${ }^{\dagger}$ Department of Economics, Bocconi University, via Roentgen 1, 20136 Milan; IFS, IGIER, and CEPR.

‡Sabanci University, Faculty of Arts and Social Sciences, Istanbul. 


\section{Introduction}

Transfer taxation has long been a highly controversial issue. Except for a brief period of time, the U.S. government has maintained a positive bequest tax ever since it was first introduced in 1916. The tax was eliminated in 2010 and reintroduced in 2011. The nature of the policy debate, however, seems to go in only one direction: in all developed countries, we indeed observe either zero or positive taxation of parental transfers. $1^{1}$

This regularity on observed tax systems around the world contrasts with the lack of a clean theoretical justification for a positive tax on bequests from an efficiency point of view ${ }^{2}$ In virtually all traditional models of bequests, efficiency calls for either zero or $a$ negative tax on parental transfers. ${ }^{3}$ Perhaps the most widely analyzed model of bequest taxation is the altruistic model, where the motive for bequests comes from the assumption that parents care about their children's welfare. A maintained assumption in the altruistic model is that different generations agree about intertemporal trade-offs. The implication of the standard altruistic model for intergenerational wealth transfers - such as bequests and inter vivos - is simple. An altruistic parent knows that the offspring will save according to his optimal plan, which is also optimal from the parent's point of view. As a result, parents do not have any paternalistic concerns regarding the offspring's savings choice and the whole dynasty acts as if it is a single individual (e.g., Bernheim (1989)). If the society cares only about the parent's welfare directly, this would imply that parental transfers are socially optimal and should remain undistorted, given that there are no other reasons for taxation such as redistribution or financing government expenditures. Following the same arguments, whenever society attaches some direct weight to future generations, parental transfers should actually be subsidized according to the altruistic model with intergenerational agreement $4^{4}$

\footnotetext{
${ }^{1}$ Estate tax rates in the United States have been varying since the time they were introduced in 1916 . For detailed information on the evolution of estate taxes in the United States, see Jacobson, Raub, and Johnson (2007). Recently, in 2013, after the expiration of the Bush tax cuts, the estate taxes increased from 35\% to 55\%. In the United Kingdom, the inheritance tax rate has held steady at $40 \%$. Both countries have an exemption level below which wealth transfers go untaxed. In the United States, this level has decreased from 5 million US dollars to 1 million US dollars in 2013. In the United Kingdom, this amount is 325,000 pounds. For detailed information on the UK inheritance tax system, visit https://www.gov.uk/inheritance-tax. For an overview on parental transfer taxation in OECD countries, see Cremer and Pestieau (2010) and OECD (2008).

${ }^{2}$ It is, of course, possible to justify taxation of parental transfers based on equality grounds. See, for instance, Piketty and Saez (2013).

${ }^{3}$ We discuss these models and their implications for bequest taxation in detail in the related literature section.

${ }^{4}$ See Kaplow (1995) and Farhi and Werning (2010) for a discussion of optimality of bequest subsidies
} 
However, disagreements are common to most, if not to all, parent-offspring relationships. Clarke, Preston, Raksin, and Bengtson (1999) studies a wide range of disagreement patterns between older parents and adult children, and develops a typology of disagreement issues. They consider a random sample of 496 parents (average age 62) and 641 children (average age 39) and ask about possible sources of disagreement. [ $^{5}$ More than $70 \%$ of the respondents report disagreements (about the same percentage among children and parents). The largest category of responses about conflict (38\% among parents and $30 \%$ among children) is labeled as Habits and Lifestyle Choices which included sexual activity/orientation, living arrangements, quality of life, and allocation of resources and or education. A conclusion the authors reach about this category of conflicts is that intertemporal allocation of resources is a common source of intergenerational disagreement. The following quote summarizes this point:

"There are also conflicts that seem to express a world view common to many in the older generation. This same father writes: 'He [39] wants all things like his generation of baby boomers, right now - new cars, new houses, vacations - all of it on one income and that a blue collar job income.' This is echoed elsewhere in another father's (60) comment over his daughter's (37) lack of 'concern for saving something for a rainy day.' Another father (71) reports that his son's (37) 'using credit cards to the limit' is an area of disagreement."

This paper analyzes optimal taxation of parental transfers in a world where parents and offspring disagree on the intertemporal allocation of resources. We show that there is a genuine efficiency reason for government intervention in the market in the presence of intergenerational disagreement. In particular, we find that, whenever offspring are impatient from parents' perspective, optimal intervention involves a positive tax on parental transfers.

We study transfer taxation using a dynastic model where people live for two periods. In the first period, people make consumption-saving decisions, and in the second period, they choose how much to consume and bequeath to their offspring. Then, they die and are replaced by an offspring who goes through the same life cycle. We model disagreement in a way that departs from the standard model minimally: a parent and an offspring agree on everything but how the offspring should allocate his resources between his young and old age.

under social preferences that weigh future generations directly.

${ }^{5}$ The exact question was: 'No matter how well two people get along, there are times they disagree or get annoyed about something. In the last few years, what are some things on which you have differed, disagreed, or been disappointed about (even if not openly discussed) with your child (or parent)?' 
In this environment, we first characterize laissez-faire market equilibrium. We focus on Markov equilibria. ${ }^{6}$ Using this characterization, we prove that equilibrium allocation is Pareto inefficient. The inefficiency stems from the fact that, as long as there is disagreement between parents and offspring, the latter do not fully internalize the consequences of their saving decisions on the former. Having uncovered an efficiency reason to intervene the market outcome, we next characterize optimal policy. We begin our analysis of optimal policy by focusing on a particular Pareto efficient allocation that we call the 'Ramsey' allocation. In this allocation, all the welfare weight is on the initial parent and future generations are valued by society only indirectly via the initial parent's welfare. The Ramsey allocation is probably the most widely adopted benchmark in the literature. This choice of the benchmark efficient allocation is further motivated by the fact that in the standard model with no disagreements a Ramsey government would find it optimal not to distort the transfer decisions of parents at all. In this sense, any need for an intervention in the case with intergenerational disagreements will be coming from nowhere else but the existence of disagreements.

We find that, if children are less patient than what their parents want them to be, then parents bequeath too much relative to the Ramsey allocation, and it is optimal for the government to correct their behavior through bequest taxation. The brief intuition for this is as follows. Due to disagreement, in the laissez-faire equilibrium, the offspring save less than the Ramsey level for their old age, which induces parents to transfer more than the Ramsey level in order to compensate for the offspring's undersaving behavior. In order to make children save the amount dictated by the Ramsey allocation, the government uses linear subsidies on savings and uses lump-sum taxes to finance these subsidies. However, from the perspective of the parents, who take the saving subsidy as given, their offspring are still undersaving under the new - subsidized - interest rate. In other words, since parents take the lump-sum tax as given, they do not internalize the fact that the subsidy is there to discipline the saving behavior of the next generation and does not actually change the gross return to their offspring's savings. As a result, the parents still transfer too much to their offspring and hence should be taxed. Even though we find the case where children are impatient from parents' perspective more natural, we also analyze the case in which they act more patiently than what their parents would like and find that bequests should be subsidized in that case.

\footnotetext{
${ }^{6}$ We cannot rule out existence of multiple equilibria, but, importantly, all the results in our paper are valid for all Markov equilibria.
} 
Next, we generalize our results to all the allocations on the Pareto frontier. We show that in general optimal bequest tax has a nice separable form between an efficiency component and an intergenerational redistribution component. The efficiency component is the same as the Ramsey bequest tax: it is only present when there is intergenerational disagreement and calls for a tax whenever offspring are impatient from parents' perspective. The second component, also present in models without intergenerational disagreements, represents a subsidy to parental transfers due to intergenerational redistribution coming from a direct weight on future generations. The overall sign of the bequest tax depends on whether the intergenerational redistribution wedge or the inefficiency wedge dominates. It is important though to note that disagreement component is positive for any Pareto efficient allocation and hence calls for a tax on parental transfers.

In addition to its policy implications, this paper also makes a methodological contribution by deriving normative implications of models with intergenerational disagreements in the absence of differentiability assumptions. In the public finance literature, it is customary to compare equilibrium and efficient allocations by defining and measuring wedges which represent discrepancies between individual and social marginal returns to individual decisions. Our results, on the other hand, are presented over three levels of analysis. In addition to analyzing optimal wedges - which requires the assumption of differentiability - and optimal taxes - which requires further restrictive assumptions implying concavity of the agents' problems - we provide a non-differentiable analysis of the discrepancies between the equilibrium allocation and the efficient allocation. Deriving normative prescriptions at this level of generality is particularly important for models with disagreements for at least two reasons. First, it is well known that, in general, these models may not have equilibria with differentiable policy functions.7 Second, even when a differentiable equilibrium exists, models with multiple selves often admit multiple (Markov) equilibria. It is important in such cases to understand whether a policy implication emerges from a general principle or, instead, it is linked to a specific equilibrium (or equilibrium property such as differentiability or linearity of the policy).

In our implementation result, we show that, when we focus our attention to linear Markov equilibria, the parental transfer wedge translates into a result on transfer taxation: efficient allocations can be implemented using linear wealth transfer taxes as long as the

\footnotetext{
${ }^{7}$ Our model with intergenerational disagreements has an analytical structure that is quite similar to models with present-bias problems a la Laibson (1997), and it is well-known that in these models policy functions that describe people's life-cycle saving behavior may not be differentiable. See Harris and Laibson (2002).
} 
government has access to (linear) life-cycle saving taxation to offset offspring's tendence to undersave. We also show that the linear Markov equilibria assumption is innocuous by proving that, under the constant elasticity of intertemporal substitution utility function (CEIS), such equilibria exist. It is important to note that the linear structure of taxes are not crucial for the optimality of taxes. As long as the saving tax applied to the offspring leaves their saving policy function strictly monotone in the amount of transfers they receive, the parents have a motive to bequeath more than efficient. This is evident from our non-differential analysis of the bequest wedge.

Related Literature. This paper is related to three strands of literature. First, as we discussed above, it is related to the literature on optimal taxation of bequests and inter vivos transfers ${ }^{8}$ Our contribution here is to provide a novel, pure efficiency argument for taxing parental transfers. In addition to the model with altruism that we discussed above, a widely used model of bequest is the warm-glow (or "joy of giving") model. In this model as well, either the optimal tax of bequests is zero or parental transfers should be subsidized to internalize the positive externality that wealth transfers induce on future generations (e.g., Kopczuk (2010)). Another framework considered in the literature is the model with exchange motives for bequests. In this class of game-theoretical models, the normative predictions crucially depend on the details of the game played between the parents and the offspring (e.g., Laitner (1997)). Finally, we have the accidental bequests model, where taxing (accidental) bequests is non-distortionary. According to this model, bequest taxes are simply a good way to finance positive government expenditures when the government has no lump-sum taxes available. This model does not imply an optimal positive tax, at least not in the way we define optimality in this paper. Specifically, there is no equilibrium inefficiency to be corrected by taxes on bequests or gifts. 9

Our paper is also related to the literature on intergenerational disagreements. A seminal paper in this literature is Phelps and Pollak (1968) which analyzes national saving rate in an environment in which each generation lives for a single period and is imperfectly altruistic: the rate at which each generation discounts next generation's consumption relative to their own consumption is higher than the rate at which they discount consumption

\footnotetext{
${ }^{8}$ See Cremer and Pestieau (2010), Kaplow (2001), and Kopczuk (2010) for excellent surveys on the literature on optimal transfer taxation.

${ }^{9}$ There is an obvious theoretical assumption - not yet carefully tested empirically - that would justify positive taxation of all sorts of wealth (not only of parental wealth transfers). It is the assumption that wealth concentration generates negative externalities. See Kopczuk (2010) for a discussion of negative wealth externalities.
} 
across any two subsequent future generations. Under the assumptions that people have CEIS utility functions, returns to capital are linear and there is no depreciation, and focusing only on the equilibrium in which all generations save the same constant fraction of their income at all periods, the paper shows that equilibrium entails lower national saving compared to the Ramsey allocation, 10 Doepke and Zilibotti (2014) analyzes an environment in which parents and children have preference disagreements, and parents can affect offspring's choices by influencing their preferences via education and by imposing direct restrictions on their choice sets. They use this model to explain the variation in parenting styles across industrialized countries and over time. Finally, Doepke and Tertilt (2009) analyzes a model where husbands and wives are imperfectly altruistic towards each other and disagree on the degree of their altruism towards their offspring. The authors use this model to explain the dramatic improvements in the legal rights of married women that occured before the introduction of female suffrage. We contribute to this growing literature by analyzing policy implications of intergenerational disagreements.

One possible interpretation of our positive model is that offspring agree with their parents regarding how much they should save but they face self-control problems that prevent them from saving the right amount. Under this interpretation, the optimal tax problem is a paternalistic one in the sense that taxes are used to correct the 'wrong' saving behavior of the offspring. This is the focus of a number of recent papers that have explored the implications of self-control problems for optimal taxation. O'Donoghue and Rabin (2003) analyze a model of paternalistic taxation for unhealthy goods. More closely related is Krusell, $\mathrm{Ku}-$ ruscu, and Smith (2010) which analyzes properties of linear taxes on life-cycle savings that implement the Ramsey allocation. Pavoni and Yazici (2012) also focus on optimal Ramsey taxation of life-cycle savings within a quasi-hyperbolic discounting model and allow for self-control problems that change with age. The current paper, on the other hand, does not assume that offspring's true welfare coincide with that of the parents. The offspring is truly more impatient than what the parent wants him to be. In this environment, we show that, independent of which member society cares about, it is optimal to tax parental transfers. The optimality of bequest taxation does not stem from correcting people's mistakes (because there are none), but rather from a positive transfer wedge that arises due to intergenerational disagreements. Since the analytical structures of the disagreement and

\footnotetext{
${ }^{10}$ Following Strotz (1955), Laibson (1997) applies this framework to individual consumption saving problem over the life cycle under self-control problems and also finds undersaving behavior. See O'Donoghue and Rabin (1999) for more general application of this model to individual decision making.
} 
self-control models are very similar, we also provide a methodological contribution to the self-control literature with our non-differential analysis of optimal policy.

The rest paper is organized as follows. Section 2 introduces the main model, and section 3 characterizes the equilibrium bequest behavior of parents in the absence of government intervention. In Section 4, we compare equilibrium and Ramsey bequest behavior and provide a tax implementation of the Ramsey allocation. In Section 5 , we provide a number of important generalizations of our result including the Pareto efficient taxation of parental transfers. Section 6 concludes.

\section{Model}

The economy is populated by a continuum of a unit measure dynasties who live for a countable infinity of periods, $t=0,1, \ldots$, where each agent within a dynasty is active for two periods. In the first period of their lives, agents are young adults and make consumption saving decisions. In the second period, they become parents, decide how much to consume and bequeath, and die. The next period their offspring becomes a young adult and goes through the same life cycle. This is a model of non-overlapping generations ${ }^{11}$ People have one unit of time endowment that they supply inelastically to the market every period. Parents bequeath because they are altruistic.

The economy begins with an initial parent in period 0 . Every subsequent even period is a parenthood period whereas every odd period is a young adulthood period. Consider a parent in some calendar year $t$. Her preference over dynastic allocation is given by

$$
V_{t}=u\left(c_{t}\right)+\gamma\left[u\left(c_{t+1}\right)+\delta V_{t+2}\right]
$$

where $\delta, \gamma \in(0,1), V_{t}$ represents the dynastic welfare of the parent in period $t, c_{t}$ is parental consumption, and $c_{t+1}$ is the first period consumption of the offspring. The instantaneous utility function, $u$, has the usual properties: strictly increasing, strictly concave, and twice differentiable, with $\lim _{c \rightarrow 0} u^{\prime}(c)=+\infty$. The parameter $\delta$ represents the (long-term) discount factor that the parent thinks the offspring and all the future descendants should save according to between their young adulthood and old adulthood periods. The parameter $\gamma$

\footnotetext{
${ }^{11}$ In Section 5.4 . we allow for a longer life cycle and show that our main results regarding bequest taxation are robust to such extension. There, we also model periods in which parents and their offspring are alive together and analyze inter vivos transfer behavior and taxation. We show that the results regarding bequest taxation extend to inter vivos transfers.
} 
is the altruism factor.

We model disagreement between parents and offspring in a way that departs from the standard dynastic framework in a minimalistic way: namely, the offspring agrees with the parent on everything except for how to allocate his wealth between young and old adulthood. Specifically, the offspring's preference is given by:

$$
u\left(c_{t+1}\right)+\beta \delta V_{t+2}
$$

In this formulation, as long as $\beta \neq 1$, the discount rate that the offspring uses between periods $t+1$ and $t+2, \beta \delta$, is different from what is appropriate from his parent's perspective, $\delta$. Parents are sophisticated in the sense that they fully anticipate this discrepancy between own and offspring's preferences ${ }^{12}$

We do not make an assumption about whether $\beta$ is smaller or larger than one from the outset. However, both the Clarke, Preston, Raksin, and Bengtson (1999) study and anecdotal evidence seems to suggest that it is more natural to consider the case where $\beta<1$. This is the case in which the offspring are impatient from the parents' perspective. It is important to note that Pareto inefficiency of laissez-faire equilibrium allocation does not depend on whether the offspring are more or less patient than what the parents would like them to be. We analyze how the sign of the optimal transfer taxes depend on the value of $\beta$ throughout the paper.

There is an alternative interpretation of the benchmark model. Under this interpretation, even though the offspring's true preference coincides with that of his parent's, i.e., he evaluates his welfare according to $u\left(c_{t+1}\right)+\delta V_{t+2}$, the offspring faces self-control problems and saves according to $u\left(c_{t+1}\right)+\beta \delta V_{t+2}$. This interpretation is in line with the literature on self-control problems in the spirit of Laibson (1997). In the current paper, on the other hand, we assume that the offspring and the parent truly disagree in the sense that $u\left(c_{t+1}\right)+\beta \delta V_{t+2}$ does not represent only offspring's behavioral preference but also his true preference.

Production takes place at the aggregate level according to the function $F\left(k_{t}, l_{t}\right)$, where $k_{t}$ and $l_{t}$ are aggregate levels of capital stock and labor in period $t$, and $F$ is a neoclassical concave production function with the usual properties: $F_{1}, F_{2}>0$ and $F_{11}, F_{22} \leq 0$. Since

\footnotetext{
${ }^{12}$ In Section 5.3, we analyze what happens if parents naively believe that their offspring agree with them regarding intergenerational resource allocation and show that our main results carry over to this case as well.
} 
each agent supplies one unit of labor inelastically, for all $t$, we have

$$
l_{t}=1 .
$$

Letting $\theta$ be the depreciation rate, this allows us to write the production function as

$$
f(k)=F(k, 1)+(1-\theta) k
$$

Letting $f\left(k_{0}\right)$ be the amount period-0 parent is endowed with, the feasibility for any $t \geq 0$ is

$$
c_{t}+k_{t+1}=f\left(k_{t}\right) .
$$

As evident from the feasibility condition above, we assume there is one representative dynasty, which implies that in any calendar year there is only one age group alive. We could, instead, allow for members of different dynasties to be at different points in their life cycles. Moreover, we could also allow for income heterogeneity by assuming, for instance, that people have different skill levels and that effective labor is given by labor times the skill level, similar to Mirrlees (1971). In the main body of the paper, we abstract from such 'horizontal' distributional issues in order to isolate our mechanism. We show in Section 5.2 that the mechanism behind our results is robust to income heterogeneity.

\section{Laissez Faire}

In this section, we characterize the equilibrium parental transfer behavior. Let $b_{t+1}$ and $b_{t+2}$ denote the bequest made by the parent in period $t$ and the offspring's saving level in $t+1$, respectively. Let $R_{t}, w_{t}$ be the interest rate and the wage rate in period $t$. Let $Q:=\left\{R_{t}, w_{t}\right\}_{t=0}^{\infty}$ be the sequence of prices that decision makers take as given. Finally, let $Q_{t}:=\left\{R_{s}, w_{s}\right\}_{s=t}^{\infty}$ be continuation of prices from period $t$ onwards.

Define $V\left(a_{t}, Q_{t}\right)$ as the value of the problem of an agent who is a parent in calendar year $t$ with $a_{t}:=R_{t} b_{t}+w_{t}$ units of wealth and who faces the price sequence $Q_{t}$. The parent's problem is given by

$$
V\left(a_{t}, Q_{t}\right)=\max _{b_{t+1} \geq-B\left(Q_{t+1}\right)} u\left(c_{t}\right)+\gamma\left[u\left(c_{t+1}\left(b_{t+1}, Q_{t+1}\right)\right)+\delta V\left(a_{t+2}\left(b_{t+1}, Q_{t+1}\right), Q_{t+2}\right)\right],
$$

subject to the budget constraints and the definition of wealth 


$$
\begin{aligned}
c_{t} & =a_{t}-b_{t+1}, \\
c_{t+1}\left(b_{t+1}, Q_{t+1}\right) & =R_{t+1} b_{t+1}+w_{t+1}-b_{t+2}\left(b_{t+1}, Q_{t+1}\right), \\
a_{t+2}\left(b_{t+1}, Q_{t+1}\right):= & R_{t+2} b_{t+2}\left(b_{t+1}, Q_{t+1}\right)+w_{t+2},
\end{aligned}
$$

together with the condition defining the policy of the offspring 13

$$
b_{t+2}\left(b_{t+1}, Q_{t+1}\right)=\arg \max _{\tilde{b}_{t+2} \geq-B\left(Q_{t+2}\right)} u\left(R_{t+1} b_{t+1}+w_{t+1}-\tilde{b}_{t+2}\right)+\beta \delta V\left(R_{t+2} \tilde{b}_{t+2}+w_{t+2}, Q_{t+2}\right) .
$$

$B\left(Q_{t}\right)$ is the 'natural' (and never binding) borrowing limit defined by requiring consumption to be non-negative at all periods:

$$
B\left(Q_{t}\right):=\sum_{s=t}^{\infty} \frac{w_{s}}{\prod_{p=t}^{s} R_{S}} .
$$

In equilibrium, prices are given by

$$
\begin{aligned}
& R_{t}=f^{\prime}\left(k_{t}\right), \\
& w_{t}=f\left(k_{t}\right)-f^{\prime}\left(k_{t}\right) k_{t},
\end{aligned}
$$

and aggregate capital and saving levels satisfy the market clearing condition

$$
k_{t}=b_{t}
$$

The parent chooses his bequest level $b_{t+1}$ taking into account the choice rule of his offspring, $b_{t+2}\left(\cdot, Q_{t+1}\right)$, which describes how offspring's saving choice changes as a function of parental bequests under a given price sequence. The parent is sophisticated in the sense that he correctly guesses his children's choice, and that is why he takes (2) into account as a constraint in his problem. Define $b_{t+1}\left(b_{t}, Q_{t}\right)$ as the policy function describing parental optimal bequeathing behavior as a function of his period $t-1$ savings and the price sequence.

A Markov equilibrium consists of a sequence of capital levels $\left\{k_{t}\right\}_{t=0}^{\infty}$, a sequence of prices $Q$, value functions $V\left(\cdot, Q_{t}\right)$ and policy functions $\left\{b_{t+1}\left(\cdot, Q_{t}\right), b_{t+2}\left(\cdot, Q_{t+1}\right)\right\}_{t=0,2,4, \ldots}$ such that: (i) the prices satisfy (3); (ii) the value function and the policies are consistent with the parent's problem; (iii) markets clear: $b_{t}=k_{t}$ for all $t$.

\footnotetext{
${ }^{13}$ To save notation, we indicate the policy as a function. In case there are multiple solutions to the offspring's problem, $b_{t+2}(\cdot)$ should be intended as a selection from the policy correspondence.
} 
Proposition 1 below characterizes equilibrium parental transfer behavior. Proving Proposition 1 would be relatively easier if we could assume the differentiability of policy function, $b_{t+2}\left(\cdot, Q_{t+1}\right)$, in bequests received. However, the dynastic intertemporal resource allocation problem with disagreements across dynasty members implies time-inconsistency in the overall dynastic problem and it is well-known from the self-control literature that in such environments we cannot guarantee even the continuity of the policy functions even when we focus our attention to Markov equilibria ${ }^{14}$ To ensure that Proposition 1 is a general feature of economies with intergenerational disagreements and not an artifact of differentiability assumptions, we prove it without making any differentiability or continuity assumptions about the value or policy functions.

Proposition 1. Suppose $\beta<1$. Then, in equilibrium,

$$
u^{\prime}\left(c_{t}\right) \geq R_{t+1} \gamma u^{\prime}\left(c_{t+1}\right)
$$

with strict inequality whenever the offspring's optimal saving policy, $b_{t+2}\left(\cdot, Q_{t+1}\right)$, is strictly monotone in the amount of the bequests received, $b_{t+1}$.

If $\beta>1$ then

$$
u^{\prime}\left(c_{t}\right) \leq R_{t+1} \gamma u^{\prime}\left(c_{t+1}\right),
$$

with strict inequality whenever the offspring's saving policy is strictly monotone in $b_{t+1}$.

If $\beta=1$, then

$$
u^{\prime}\left(c_{t}\right)=R_{t+1} \gamma u^{\prime}\left(c_{t+1}\right) .
$$

Proof. Relegated to Appendix A.1.

Even though we prove the proposition for both cases of disagreement, $\beta<1$ and $\beta>1$, based on anecdotal evidence, we believe that the case in which children save suboptimally from their parents' perspective, $\beta<1$, is more relevant. This is also supported by the limited empirical evidence we have from Clarke, Preston, Raksin, and Bengtson (1999). We provide intuition only for this case, the intuition for the $\beta>1$ case is symmetric. To get a better grasp of what the proposition says, first focus on the case in which the child and parent agree on inter-temporal trade offs, meaning $\beta=1$. In that case, the parent chooses

\footnotetext{
${ }^{14}$ See Morris and Postlewaite (1997) and Harris and Laibson (2002) for examples of economies with quasihyperbolic discounters where policy functions are discontinuous. Krusell and Smith (2003) shows that even when we focus attention to Markov equilibria, it is not possible to rule out the existence of discontinuous equilibria. Notice that the discontinuity in these models is due to a 'disagreement' across an agent's multiple selves whereas in our model the disagreement is across different generations.
} 
the level of transfers to equate the marginal cost of his forgone consumption (left-hand side of (6) ) to the marginal benefit of his child's increased consumption in period $t+1$ (right-hand side of (6)). However, when $\beta<1$, then, as seen from (4), the parent keeps increasing transfers even after the marginal cost is equated to the marginal benefit from increased child consumption in period $t+1$. The parent does this because bequeathing has an additional marginal benefit from the parent's perspective when the offspring is impatient. Intuitively, when $\beta<1$, the offspring is undersaving from the parent's perspective. The parental welfare goes up if the parent can make the offspring increase his savings, which is possible by increasing bequests as long as the offspring's optimal saving policy is strictly increasing in the amount of bequests received. This means increasing bequests carries an additional benefit. We will provide a sharper marginal characterization of equilibrium bequest behavior in Section 3.2 where we assume differentiability of the value and policy functions. This sharper characterization will also enable us to sharpen the intuition explained above. But, before that, we prove that laissez-faire equilibrium is inefficient in Section 3.1 .

\subsection{The Inefficiency of Laissez-Faire Equilibrium}

We show that the laissez-faire equilibrium is Pareto inefficient whenever $\beta \neq 1$. Importantly, the proof uses a perturbation argument and does not use any differentiability or continuity assumptions regarding the equilibrium value or policy functions. This is important because we know from Krusell and Smith (2003) that in models similar to ours there can be many Markov equilibria some of which might have discontinuous policy functions. By not making any assumptions on continuuty or differentiability, our proof ensures that Pareto inefficiency applies to the whole class of Markov equilibria.

It is important to understand that the sense in which equilibria are inefficient are very different between our disagreement economy and the related self-control economy. According to the self-control interpretation, offspring want to save according to $\delta$ discounting but lack the self-contol and end up saving according to $\beta \delta$ discounting. Here, if we increase the offspring's savings by a small amount, this improves the welfare of both the offspring and the parent, implying that original equilibrium cannot be efficient. The inefficiency stems from the fact that some agents cannot carry out actions that are optimal from everybody's perspective. In the disagreement economy, the $\beta \delta$ discounting represents offspring's true preference, and thus, a perturbation that simply increases offspring's saving 
rate cannot Pareto improve over equilibrium because it makes the offspring worse off. The inefficiency of laissez-faire equilibria in the disagreement economy comes purely from the existence of a consumption externality that arises from the presence of disagreement 15

Proposition 2 states and proves that as long as $\beta \neq 1$ the laissez-faire equilibrium allocation is Pareto inefficient. The proof provides a resource feasible perturbation of the equilibrium allocation that improves welfare of all agents in all preceding and present generations and leaves welfare constant to all subsequent generations to the perturbation.

Proposition 2. The laissez-faire equilibrium allocation is Pareto inefficient.

Proof. Relegated to Appendix A.2.

The intuition for the inefficiency of equilibrium is as follows. As it is evident from equation (7) below, the parent's welfare, $V_{t}$, depends on how much the offspring saves. In this sense, there is a consumption externality. Obviously, this is true in the standard altruistic model without disagreements as well (see Bernheim (1989)). In the standard case, however, since offspring fully agrees with the parent, in a sense the offspring internalizes the consequences of his saving on the parent, so the externality does not have a consequence. This can be seen by setting $\beta=1$ in equation (7) below.

$$
V_{t}=u\left(c_{t}\right)+\gamma[\underbrace{u\left(c_{t+1}\right)+\beta \delta V_{t+2}}_{\text {offspring welfare }}+(1-\beta) \delta V_{t+2}]
$$

When $\beta \neq 1$, the offspring does not fully internalize the consequences of his saving on parental welfare. The level of savings he chooses affects the term $(1-\beta) \delta V_{t+2}$ in (7), but this term is external to the offspring. This externality is the reason why equilibrium is inefficient. In the case in which $\beta<1$, the term that creates the externality asks for a higher saving rate. In this case, the planner can improve both agents' welfare by forcing the offspring to increase his savings by a small amount. This creates a second order loss for the offspring since he was already at his optimal allocation. It creates a first order gain for the parent since the equilibrium level of offspring saving is strictly suboptimal from parent's perspective. Then, the planner simply transfers a suitable amount from the parent

\footnotetext{
${ }^{15}$ In this case, the criterion we use is sometimes referred as the multi-self Pareto criterium (see Bhattacharya and Lakwalla, NBER 2004).Here the ancillarity conditions are rectangular so we can even be consistent with Choice-theoretical approach of Berheim and Rangel, QJE 2009. This footnote needs clarification. Also, I couldnt find the paper you are citing here online.
} 
to the offspring to compensate the second-order decline in offspring's welfare, achieving the desired Pareto improvement.

\subsection{Equilibrium Parental Behavior under Differentiability}

In this section, we provide a marginal condition that characterizes equilibrium bequest behavior assuming differentiability of the policy functions which describe offspring's savings. Recall that $b_{t+2}\left(\cdot, Q_{t+1}\right)$ represents the offspring's equilibrium choice under price sequence $Q_{t+1}$ as a function of the bequests he receives from his parent, $b_{t+1}$. Now consider a parent's problem. The parent chooses $b_{t+1}$ subject to the flow budget constraints and the function $b_{t+2}\left(\cdot, Q_{t+1}\right)$, defined by (2), which describes offspring saving decision. The parent's first-order optimality condition with respect to the bequest decision, $b_{t+1}$, is

$u^{\prime}\left(c_{t}\right)=\gamma\left(u^{\prime}\left(c_{t+1}\right)\left[R_{t+1}-\frac{\partial b_{t+2}\left(b_{t+1}, Q_{t+1}\right)}{\partial b_{t+1}}\right]+\delta V_{1}\left(a_{t+2}, Q_{t+2}\right) R_{t+2} \frac{\partial b_{t+2}\left(b_{t+1}, Q_{t+1}\right)}{\partial b_{t+1}}\right)$,

where $V_{1}$ refers to the derivative of the value function with respect to its first argument and the derivatives are all evaluated at the equilibrium allocation.

Observe that the offspring's first-order optimality condition for $b_{t+2}$ is given by

$$
u^{\prime}\left(c_{t+1}\right)=\beta \delta V_{1}\left(a_{t+2}, Q_{t+2}\right) R_{t+2}
$$

Using (9) in the parental optimality condition (8), we get the following proposition which describes equilibrium parental bequeathing behavior under differentiability.

Proposition 3. Suppose $b_{t+2}\left(\cdot, Q_{t+1}\right)$ is differentiable in $b_{t+1}$. The equilibrium bequest behavior is characterized by

$$
u^{\prime}\left(c_{t}\right)=\gamma\left(R_{t+1} u^{\prime}\left(c_{t+1}\right)+\frac{\partial b_{t+2}\left(b_{t+1}, Q_{t+1}\right)}{\partial b_{t+1}} u^{\prime}\left(c_{t+1}\right)\left[-1+\frac{1}{\beta}\right]\right) .
$$

Equation (10) is the usual savings optimality condition, with an additional term on the right-hand side. The left-hand side is the marginal cost of increasing bequests, which equals the utility loss from forgone parental consumption. The first term on the right-hand side is the usual marginal benefit of increasing saving - the utility gain from increased consumption in the period during which returns to savings are received. There is a second term on the right-hand side, however. One can see that this term does not show up in the 
solution to the usual savings problems where $\beta=1$, meaning the saver and the person receiving savings agree on what the receiver will do with the savings (an implication of the Envelope condition). This additional term summarizes how increasing parental transfers affects parental welfare by affecting the consumption levels of the offspring. It is a multiplication of two terms: the first term,

$$
\frac{\partial b_{t+2}\left(b_{t+1}, Q_{t+1}\right)}{\partial b_{t+1}}>0
$$

tells how the offspring's saving is affected by an increase in bequests. In general, this derivative is weakly positive since increasing transfers increases the period $t+1$ wealth of the offspring, which weakly increases his savings. As we show in Lemma 16 in Appendix A.1. under the assumption of differentiability of $b_{t+2}\left(\cdot, Q_{t+1}\right)$, this derivative is strictly positive 16

The second term,

$$
=u^{\prime}\left(c_{t+1}\right)\left[-1+\frac{1}{\beta}\right],
$$

represents the utility value to the parent of increasing $b_{t+2}$ marginally and is positive (resp. negative) whenever $\beta<1$ (resp. $\beta>1$ ).

Intuitively, when $\beta<1$, the parent knows that from his perspective the offspring is undersaving. So, parental welfare goes up if the parent can make the offspring increase his savings, which is possible by increasing bequests since $\frac{\partial b_{t+2}\left(b_{t+1}, Q_{t+1}\right)}{\partial b_{t+1}}>0$. As a result, the additional term in (10) is positive: there is an additional marginal benefit of increasing transfers for the parent. It is this extra benefit of bequeathing that makes the parent behave according to (4). Observe that under differentiability the strict version of equation (4) holds.

\section{Ramsey}

In Section 3.1. we show that laissez-faire equilibrium is unambiguously Pareto inefficient. The optimal policy implications of such result might obviously depend on the particular Pareto efficient allocation the policy targets. In this section, we start our optimal bequest tax policy analysis by targeting a widely adopted benchmark Pareto efficient allocation, namely the 'Ramsey' allocation. The Ramsey allocation is the efficient allocation that puts

\footnotetext{
${ }^{16}$ To be precise, Lemma 16 proves that as long as the value function is differentiable, the policy is strictly monotone. The differentiability of the value function is implied by differentiability of the policy function.
} 
all the weight on the initial generation parent. Thus, it is given by the solution to a fictitious social planner's consumption-saving problem where the planner discounts exponentially at rate $\delta$ between young and old adulthood and discounts future generations by altruism factor $\gamma$. In Section 5.1, we analyze Pareto efficient optimal bequest policy and show that the mechanism behind the optimality of bequest taxes that we find in the current section continues to exist when we target any Pareto efficient allocation.

The Ramsey allocation has at least three desirable properties. First, it corresponds to the equilibrium allocation in absence of conflict about intertemporal trade offs. Thus, in the absence of disagreements, optimal policy is simply not to distort bequests at all. In that sense, in the case of Ramsey allocation, the optimality of bequest tax under disagreements is coming purely from disagreements. Second, it is unique and simple to characterize, as it is the dynastic solution to the standard Ramsey-Cass-Koopmans optimal growth problem. Finally, the life-cycle allocation of resources in this allocation - saving according to discount factor $\delta$ - is optimal from the perpective of all the agents in the dynasty except for the current young adult. 17

We first characterize the Ramsey allocation. Then, we show that the Ramsey level of bequests does not satisfy the parent's optimality condition in laissez-faire equilibrium: in particular, parents bequeath too much relative to the Ramsey level when offspring are impatient from parents' perspective. This implies that implementing the Ramsey allocation in the market requires government intervention. We show that, under differentiability assumptions on offspring's saving policy function, this result translates into an optimal positive bequest wedge. Finally, we provide an implementation of the Ramsey allocation in the market through linear taxes on savings and bequests for a special class of equilibria. The optimal tax on bequests is positive.

In Section 5.1. we generalize our results to all the allocations on the Pareto frontier. ${ }^{18}$ There, we show that optimal bequest wedge has a nice separable form between an efficiency component and an intergenerational redistribution component. The efficiency component is similar to the Ramsey bequest wedge that we derive in this section in that it is due to intergenerational disagreement: whenever $\beta=1$, this component disappears. The second component, also present in models without any intergenerational disagreements, represents a subsidy to parental transfers due to intergenerational redistribution coming

\footnotetext{
${ }^{17}$ Evaluating welfare from the perspective of the initial self is also the route taken in much the literature on self-control problems. See DellaVigna and Malmendier (2004), Gruber and Koszegi (2004) and O'Donoghue and Rabin (2006), for example.

${ }^{18}$ Along this line, also see Farhi and Werning (2010), Kaplow (1995), and Kaplow (2001).
} 
from a direct weight on the offspring.

\subsection{The Ramsey Allocation}

The Ramsey allocation is unique, and given by the solution to a fictitious social planner's consumption saving problem where the planner has altruism and discount factors $\gamma$ and $\delta$, respectively. The following Euler equations characterize the Ramsey levels of bequests and savings, which we denote with an asterisk: 19 for all $t$ even,

$$
\begin{aligned}
u^{\prime}\left(c_{t}^{*}\right) & =\gamma f^{\prime}\left(k_{t+1}^{*}\right) u^{\prime}\left(c_{t+1}^{*}\right), \\
u^{\prime}\left(c_{t+1}^{*}\right) & =\delta f^{\prime}\left(k_{t+2}^{*}\right) u^{\prime}\left(c_{t+2}^{*}\right) .
\end{aligned}
$$

\subsection{The Ramsey Wedge}

Now we turn to the implications of Proposition 1 for equilibrium wealth transfer behavior relative to the Ramsey allocation. Comparison of Ramsey condition for bequests, (11), with the equilibrium condition, (4) , together with the equilibrium pricing condition $R_{t+1}=$ $f^{\prime}\left(k_{t+1}\right)$ implies that the equilibrium level of parental transfers does not satisfy the Ramsey condition for bequests. In the Ramsey allocation, the offspring's choice of savings is optimal from parents' perspective, which implies that the only marginal benefit of bequests comes from increased offspring consumption in the next period. On the other hand, in equilibrium, parents find an additional benefit to bequeathing: compensating for offspring's period $t+1$ undersaving behavior. Therefore, the parent will keep increasing his transfers beyond the Ramsey level. We summarize this result with the following corollary.

Corollary 4. If $\beta<1$ (resp. $\beta>1$ ) then a parent with a Ramsey level of wealth and facing Ramsey interest rate $f^{\prime}\left(k_{t+1}^{*}\right)$ bequeaths more (resp. less) in equilibrium compared to Ramsey level of bequests.

Proof. Follows from comparison of conditions (11) and (4) (resp. 5) and the strict concavity of $u$.

\footnotetext{
${ }^{19}$ In Section 5 , we denote any generic Pareto efficient allocation by asterisk in an effort to keep notational simplicity.
} 
If we assume differentiability of policy functions, Corollary 4 translates into a positive bequest wedge for $\beta<1$. To see this, first define the Ramsey bequest wedge as:

$$
B W_{t}^{*}=1-\left(\frac{u^{\prime}\left(c_{t}^{*}\right)}{\gamma u^{\prime}\left(c_{t+1}^{*}\right) R_{t+1}^{*}}-\frac{\partial b_{t+2}\left(b_{t+1}^{*}, Q_{t+1}^{*}\right)}{\partial b_{t+1}} \frac{\left[-1+\frac{1}{\beta}\right]}{R_{t+1}^{*}}\right),
$$

where $Q_{t+1}^{*}$ corresponds to the price sequence implied by the Ramsey allocation, that is $Q_{t+1}^{*}:=\left\{R_{t+s}^{*}, w_{t+s}^{*}\right\}_{s=1}^{\infty}=\left\{f^{\prime}\left(k_{t+s}^{*}\right), f\left(k_{t+s}^{*}\right)-f^{\prime}\left(k_{t+s}^{*}\right) k_{t+s}^{*}\right\}_{s=0}^{\infty}$, and the function $b_{t+2}\left(\cdot, Q_{t+1}^{*}\right)$ is equilibrium policy of the offspring under that price sequence. Recall that parents bequeath according to 10 in equilibrium. The Ramsey bequest wedge in period $t$ measures the efficient marginal distortion that the planner needs to create in the return to bequests, $R_{t+1}^{*}$, in order to make the parent choose the Ramsey level of bequests in equilibrium. A positive (negative) $B W_{t}$ means that a parent facing the Ramsey interest rate, $R_{t+1}^{*}=f^{\prime}\left(b_{t+1}^{*}\right)$, would like to increase (decrease) his bequests marginally above (below) the Ramsey level if there is no government intervention.

Corollary 5. Suppose $b_{t+2}\left(\cdot, Q_{t+1}\right)$ is differentiable in $b_{t+1}$ and $\beta<1$. Then $B W_{t}^{*}>0$.

Proof. Using equation (11) in the definition of $B W_{t}^{*}$, we get

$$
B W_{t}^{*}=\frac{\partial b_{t+2}\left(b_{t+1}^{*}, Q_{t+1}^{*}\right)}{\partial b_{t+1}} \frac{\left[-1+\frac{1}{\beta}\right]}{R_{t+1}^{*}} .
$$

Lemma 16 in Appendix A.1 shows that when $b_{t+2}\left(\cdot, Q_{t+1}\right)$ is differentiable in $b_{t+1}$, then $\frac{\partial b_{t+2}\left(b_{t+1}^{*}, Q_{t+1}^{*}\right)}{\partial b_{t+1}}>0 . B W_{t}^{*}>0$ then follows from $0<\beta<1$.

Both the Ramsey planner and the parents in equilibrium face a marginal return equal to $R_{t+1}^{*}$ when bequeathing. For the parent, there is an additional return though: since in equilibrium the offspring is undersaving from parent's perspective, a marginal increase in bequests increases parental welfare by increasing the offspring's savings. In order to alling parent's marginal return with the Ramsey return, the planner needs to decrease equilibrium interest rate by (14), which is equal to that additional return normalized by Ramsey return. Notice that the bequest wedge is strictly positive since, under differentiability assumption, offspring's saving is strictly increasing in the bequests received which implies that the additional return to bequeathing is strictly positive. 


\subsection{Implementation: Ramsey Taxation of Bequests}

In this section, we want to implement the Ramsey allocation through a linear tax system on life-cycle savings and parental wealth transfers. Let $\tau_{t+1}$ denote the linear tax rate on returns to period $t$ savings, $b_{t+1}$. If $t$ is a period of parenthood, then $\tau_{t+1}$ is a tax on bequests. Tax proceeds are rebated in a lump-sum manner in every period, so that the government balances its budget period by period. Letting $T_{t}$ denote lump-sum taxes in period $t$,

$$
T_{t}=R_{t} \tau_{t} b_{t}
$$

Let $Y:=\left\{\tau_{t}, T_{t}\right\}_{t=0}^{\infty}$ be the sequence of taxes that the government chooses and commits to at the beginning of time and $Y_{t}:=\left\{\tau_{s}, T_{s}\right\}_{s=t}^{\infty}$. Let $Y^{*}:=\left\{\tau_{t}^{*}, T_{t}^{*}\right\}_{t=0}^{\infty}$ denote a tax system that implements the Ramsey allocation. We are interested in the Ramsey taxes on wealth transfers.

Letting $\Psi:=(Q, Y)$ be the joint sequence of prices and taxes, let $\Psi_{t}:=\left(Q_{t}, Y_{t}\right)$. Define $V_{t}\left(a_{t}, \Psi_{t}\right)$ as the problem of a parent with wealth level $a_{t}$ in calendar year $t$ facing $\Psi_{t}$, where the wealth level is $a_{t}:=R_{t} b_{t}\left(1-\tau_{t}\right)+T_{t}+w_{t}$. The parent's problem is given by

$$
V\left(a_{t}, \Psi_{t}\right)=\max _{b_{t+1} \geq-B\left(\Psi_{t+1}\right)} u\left(c_{t}\right)+\gamma\left[u\left(c_{t+1}\left(b_{t+1}, \Psi_{t+1}\right)\right)+\delta V\left(a_{t+2}\left(b_{t+1}, \Psi_{t+1}\right), \Psi_{t+2}\right)\right]
$$

subject to the budget constraints

$$
\begin{aligned}
c_{t} & =a_{t}-b_{t+1}, \\
c_{t+1}\left(b_{t+1}, \Psi_{t+1}\right) & =R_{t+1} b_{t+1}\left(1-\tau_{t+1}\right)+T_{t+1}+w_{t+1}-b_{t+2}\left(b_{t+1}, \Psi_{t+1}\right), \\
a_{t+2}\left(b_{t+1}, \Psi_{t+1}\right) & =R_{t+2} b_{t+2}\left(b_{t+1}, \Psi_{t+1}\right)\left(1-\tau_{t+2}\right)+T_{t+2}+w_{t+2},
\end{aligned}
$$

and the offspring's policy function is defined as

$$
b_{t+2}\left(b_{t+1}, \Psi_{t+1}\right)=\arg \max _{\tilde{b}_{t+2} \geq-B\left(\Psi_{t+2}\right),} u\left(\tilde{c}_{t+2}\right)+\beta \delta V\left(\tilde{a}_{t+2}, \Psi_{t+2}\right),
$$

subject to

$$
\begin{aligned}
& \tilde{c}_{t+2}=R_{t+1} b_{t+1}\left(1-\tau_{t+1}\right)+T_{t+1}+w_{t+1}-\tilde{b}_{t+2}, \\
& \tilde{a}_{t+2}=R_{t+2} \tilde{b}_{t+2}\left(1-\tau_{t+2}\right)+T_{t+2}+w_{t+2} .
\end{aligned}
$$


The natural debt limit under $\Psi_{t}$ is given by

$$
B\left(\Psi_{t}\right):=\sum_{s=t}^{\infty} \frac{w_{s}+T_{s}}{\Pi_{p=t}^{s} R_{s}\left(1-\tau_{s}\right)} .
$$

Note that the offspring's optimal policy is also a function of taxes.

In general, an agent's problem at any age is not convex since each parent faces a constraint describing the offspring's policy, which may potentially break the convexity of the constraint set. Therefore, showing that the first-order optimality conditions of agents are satisfied by the Ramsey allocation under a tax system does not guarantee that the tax system implements the Ramsey allocation. As a result, Proposition 1 does not automatically imply that there is a linear tax system that implements the Ramsey allocation. Therefore, we restrict attention to Markov equilibria with policy functions that are linear in current wealth. The linearity of the policy functions guarantees that agents' constraint sets are convex, thus implying that their problems are concave. Hence, we have the following implementation result.

Proposition 6. Suppose (Markov) equilibrium (with taxes) admits policies that are linear in current wealth. Then, there is a linear tax system that implements the Ramsey allocation. In this system, policies are strictly increasing, and optimal bequest taxes are strictly positive if and only if $\beta<1$. They are given by

$$
\tau_{t+1}^{*}=\left(-1+\frac{1}{\beta}\right) M_{t+2}\left(\Psi_{t+1}^{*}\right) \frac{1}{R_{t+1}^{*}}>0,
$$

where

$$
M_{t+2}\left(\Psi_{t+1}^{*}\right)=\frac{\partial b_{t+2}\left(b_{t+1}^{*}, \Psi_{t+1}^{*}\right)}{\partial b_{t+1}}>0
$$

is the coefficient of offspring's (linear) policy function under the Ramsey tax system and prices implied by the Ramsey allocation.

Proof. The linearity of the policy functions implies that each agent's problem is concave, which implies that, once feasibility is guaranteed, the parent's first-order optimality conditions are necessary and sufficient for the equilibrium. It is easy to derive the optimality condition for parental bequest choice under taxes, analogous to (10) :

$$
u^{\prime}\left(c_{t}\right)=\gamma u^{\prime}\left(c_{t+1}\right)\left(R_{t+1}\left(1-\tau_{t+1}\right)+\frac{\partial b_{t+2}\left(b_{t+1}, \Psi_{t+1}\right)}{\partial b_{t+1}}\left\{-1+\frac{1}{\beta}\right\}\right) .
$$


Substituting in the Ramsey allocation and using (11) gives tax expression in the statement of Proposition 6 above. The fact that $M_{t+2}\left(\Psi_{t+1}^{*}\right)$ is strictly positive follows from the differentiability of offspring's policy function.

Next, we show that when the utility function is of the CEIS form, there is always a Markov equilibrium with policy functions that are linear in current wealth 20

Proposition 7. Suppose period utility is of the CEIS form, meaning

$$
\begin{aligned}
u(c) & =\frac{c^{1-\rho}}{1-\rho}, \text { for } \rho \in(0,1) \text { and } \rho>1 ; \\
& =\log (c), \text { for } \rho=1 .
\end{aligned}
$$

Then, if an equilibrium with taxes exists, there is an equilibrium in which consumption in each period is a linear function of the net present value of wealth as of that period.

Proof. Relegated to Appendix A.3.

It is interesting to note that even though the government corrects offspring's saving behavior through saving taxes, parental transfers should still be taxed to achieve the Ramsey allocation. Here, one might ask: given that from the Ramsey perspective the offspring is saving the right amount (thanks to corrective taxes), why does the parent still bequeath more than the Ramsey level? This occurs because, from the parent's perspective, the offspring is undersaving. The taxes that are levied on the offspring create a diversion between the parent's and the planner's perception of what is optimal for the offspring. The planner knows that the lump-sum taxes required to balance its budget in period $t+2$ equal $T_{t+2}=R_{t+2} \tau_{t+2} b_{t+2}$. Thus, the return to the savings of the offspring in any period $t+1$ is actually $R_{t+2}$, and the taxes are there only to drive the children to Ramsey behavior. The parent, on the other hand, takes lump-sum taxes as given and, hence, sees the return as $R_{t+2}\left(1-\tau_{t+2}\right)$, and wants the child to save optimally according to this return. So, the Ramsey level of saving that the planner makes the offspring save is still too low from the parent's perspective at the interest rate $R_{t+2}\left(1-\tau_{t+2}\right)$. As a result, the parent still has a motive to transfer more than the Ramsey level. To discourage this, we need a tax on bequests. Another way of interpreting this result is as follows. By bequeathing an extra unit to the offspring the parents increase their saving, which increases the cost for the government as

\footnotetext{
${ }^{20}$ For a special case of our model economy with partial equilibrium and constant prices, Phelps and Pollak (1968) and Laibson (1994) have shown existence of linear equilibria under CEIS utility.
} 
it has to pay the subsidy. Hence, bequest generate a negative fiscal externality. The tax on bequest is a pigouvian tax needed to internalise such externality.

We know that if the government (or the parents) could command the offspring to the Ramsey allocation, then there is no need to distort parents' bequest decision. A natural question that follows, then, is whether the bequest tax result is peculiar to the assumption that the government is restricted to use linear taxes to discipline the offspring's problem. The proof of Proposition 1 shows that as long as the offspring react to an increase in bequests by increasing their savings, parents will have the extra return to bequeathing, and hence, will bequeath too much if they are not taxed. Therefore, as long as the government policy leaves offspring's optimal saving policies strictly increasing in the bequests they receive, parents will bequeath too much if they are not taxed. If the offspring do not change their behavior as a consequence of the parent's decisions there is no fiscal externality. Fiscal externality emerges as a consequence of offsoring's extra savings. We conclude that the optimality of the bequest tax is not peculiar to the implementation in which there are linear taxes on children's savings; bequest taxes would remain optimal for any tax system that does not eliminate the monotonicity of offspring's optimal saving policies in the amount of bequests they receive.

Finally, note that, implicit in the Markovianity assumption, we do not allow for conditional bequests. In particular, parents are not allowed to condition the payment of the bequest to a specific level of savings by the offspring. The lack of such - potentially welfare improving - arrangements might be justified by the fact that they are difficult to enforce in reality. Recall, indeed, that bequest payments - by definition - occur after parents die and saving decisions might be difficult to monitor, especially by third parties. In this sense, "Rotten Kid Theorem" of Becker (1974) does not hold in our environment by assumption.

\subsection{Back of the Envelope Quantification of Our Mechanism}

Our main result states that, as long as children - the recipients of intergenerational transfers - are too impatient from their parents' perspective, parents transfer too much, and hence, to restore efficiency, bequests should be taxed.

In this section we aim to shed some light on the quantitative importance of our mechanism for bequest taxation. To do so, we compute optimal bequest taxes that implement the Ramsey allocation for a parameterized version of our economy. We focus on logarithmic 
utility which allows us to find closed-form solutions for optimal bequest taxes.

Proposition 8. Suppose $u(c)=\log (c)$. Then, the optimal bequest tax in any period of parenthood $t$ is given by the following formula:

$$
1-\tau_{t+1}^{*}=\frac{1+\beta \delta D}{1+\delta D}, \quad \text { where } D=\frac{1+\gamma}{1-\delta \gamma} .
$$

Proof. Relegated to Appendix A.4.

Observe that, under the logarithmic utility function assumption, the tax formula does not depend on the shape of the production function, $F$, or the depreciation rate, $\theta$. Therefore, we do not need to specify values for these parameters. The only parameters that are needed to calculate optimal taxes are the discount factor $\delta$, the altruism factor, $\gamma$, and the parameter $\beta$ which represents the degree of disagreement. Remember that people live for two periods of adulthood in our model. We set each period length to be 25 years and annual discount factor to be 0.98 . This implies that $\delta=0.98^{25} \approx 0.6$. We assume perfect altruism in the sense that parents discount their offspring's consumption as much as they discount their own consumption, i.e., $\gamma=\delta$. Inspired by the present-bias literature, we vary $\beta$ between 0.5 and 0.9 to cover values of $\beta$ that are estimated by Laibson, Repetto, and Tobacman (2007). The following table summarizes the optimal bequest tax rates for different values of $\beta$.

\begin{tabular}{|c|c|c|c|c|c|}
\hline$\beta$ & 0.5 & 0.6 & 0.7 & 0.8 & 0.9 \\
\hline bequest tax & $30.1 \%$ & $24.1 \%$ & $18.1 \%$ & $12.1 \%$ & $6 \%$ \\
\hline
\end{tabular}

We conclude that the optimal taxes generated by our mechanism might be quantitatively significant.

\section{Extensions}

In this section, we consider several extensions of the baseline framework. First and foremost, we show that the optimality of creating a positive bequest wedge that is needed to implement the Ramsey allocation shown in Section 4 holds when the target is implementing any other allocation on the Pareto frontier. Next, we extend our model by introducing horizontal inequality and show that bequest taxation is still optimal. Moreover, we show 
that optimal bequest taxes are typically progressive. Third, we show that if we instead assume that people are naive in the sense that they are not aware of the disagreements with their descendants, the bequest tax result still holds. Finally, we show that our normative results are also robust to extending people's life cycle to any finite periods and allowing parents and offspring to coexist in the same period. This also allows us to show that it is optimal to tax inter vivos transfers as well.

\subsection{Intergenerational Distribution Motives}

The Ramsey allocation is one of the many possible Pareto efficient allocations. Namely, it constitutes one particular point on the Pareto frontier. In this section, we study other Pareto efficient allocations and characterize wedges that need to be created to implement these allocations in equilibrium.

We begin by characterizing Pareto efficient allocations. Let $\mathbf{U}=\left\{U_{n}\right\}_{n=1}^{\infty}$ be any given sequence of utilities where $U_{n} \in \mathbb{R}$ represents the minimum level of utility that needs to be delivered to people of generation $n$ (who are born in calendar time $2 n-1$ ) starting with the agent born in period 1 . Let $\mathcal{U}$ be the set of such utility sequences that are achievable by feasible allocations 21

We compute a Pareto efficient allocation solving a planning problem where we maximize the utility of one agent, initial parent, subject to delivering other agents $\mathbf{U}$. By changing $\mathbf{U}$ in the set of all feasible utility sequences $\mathcal{U}$, the solution to this planning problem traces the whole Pareto frontier of the economy.

We propose a simple recursive formulation of the planning problem as follows. If $k$ is the level of capital at the beginning of parenthood in a given generation, the value function

\footnotetext{
${ }^{21}$ A key feature restricting the set $\mathcal{U}$ is the domain of $u: \mathbb{R}_{+} \rightarrow \mathbb{R}$. Moreover, it is well known that, with a positive rate of depreciation and Inada on $f$ at infinity, there is a $\bar{k}$ such that $f(k)<k \forall k \geq \bar{k}$. So, as a minimal requirement, for all $n$ it must be that $U_{n} \in[u(0), u(\bar{k})]$. If $u(0)>-\infty$, to be achievable, a sequence of utilities $\mathbf{U}$ must admit a sequence of capital levels $\left\{k_{t}\right\}_{t=0}^{\infty}$ such that, for all $t$, we have $0 \leq k_{t+1} \leq f\left(k_{t}\right)$ and for generation $n$ who are born in period $s=2 n-1$

$U_{n}=u\left(f\left(k_{s}\right)-k_{s+1}\right)+\beta \delta\left\{u\left(f\left(k_{s+1}\right)-k_{s+2}\right)+\sum_{t=s+1}^{\infty} \gamma^{t-s} \delta^{t-s-1}\left[u\left(f\left(k_{2 t-1}\right)-k_{2 t}\right)+\delta u\left(f\left(k_{2 t}\right)-k_{2 t+1}\right)\right]\right\}$.
} 
representing the planner value of parent's utility, $W: K \times \mathcal{U} \rightarrow R$ solves: ${ }^{22}$

$$
\begin{gathered}
W(k, \mathbf{U})=\max _{y, k^{\prime}} \quad u(f(k)-y)+\gamma\left[u\left(f(y)-k^{\prime}\right)+\delta W\left(k^{\prime}, \mathbf{U}^{\prime}\right)\right] \\
\text { s.t. } \quad 0 \leq y \leq f(k), \quad 0 \leq k^{\prime} \leq f(y) \\
u\left(f(y)-k^{\prime}\right)+\beta \delta W\left(k^{\prime}, \mathbf{U}^{\prime}\right) \geq U .
\end{gathered}
$$

In the above notation, $\mathbf{U}^{\prime}$ indicates the continuation of $\mathbf{U}^{23}$ The choice variables $y$ and $k^{\prime}$ represent, respectively, the bequest decision of the parent and the saving decision of the offspring. Constraint (15) guarantees that each new generation gets a level of utility $U$. By choosing any sequence of utilities we span the whole Pareto frontier.

Since the problem is concave in the choice variables for each $(k, \mathbf{U})$, it can be shown that the value function $V$ is concave in $k$. An application of Benveniste and Sheinkman lemma implies that (since $u$ is differentiable) $V$ is differentiable in the first argument for all $\mathbf{U} \in \mathcal{U}{ }^{24}$ Let $g: K \times \mathcal{U} \rightarrow R_{+}$be the policy function for $y$ and $h: K \times \mathcal{U} \rightarrow R_{+}$. The envelope theorem implies that

$$
W_{1}(k, \mathbf{U})=f^{\prime}(k) u^{\prime}(f(k)-g(k, \mathbf{U})),
$$

whenever $0<g(k, \mathbf{U})<f(k)$, where $W_{1}$ refers to the derivative of $\mathrm{W}$ with respect to first argument.

If we denote by $\lambda$ the multiplier associated to constraint (15), the first order conditions for optimality are:

$$
\begin{array}{ll}
y \text { (bequest): } & u^{\prime}(f(k)-y)=(\gamma+\lambda) f^{\prime}(y) u^{\prime}\left(f(y)-k^{\prime}\right) \\
k^{\prime} \text { (savings): } & u^{\prime}\left(f(y)-k^{\prime}\right)=\delta \frac{\gamma+\lambda \beta}{\gamma+\lambda} f^{\prime}\left(k^{\prime}\right) u^{\prime}\left(f\left(k^{\prime}\right)-y^{\prime}\right) .
\end{array}
$$

Once we solve for the policy functions $g$ and $h$, we can use them to construct the Pareto efficient sequence of capital stocks in the usual way. First, let $\mathbf{U}_{1}=\left\{U_{n}\right\}_{n=1}^{\infty}$ be the sequence that represents a particular Pareto efficient allocation. Define $\mathbf{U}_{m}=\left\{U_{n}\right\}_{n=m}^{\infty}$. Then, define capital allocation under this efficient allocation recursively as: $k_{1}^{*}=g\left(k_{0}, \mathbf{U}_{1}\right)$,

\footnotetext{
${ }^{22} \mathrm{~K} \equiv[0, \bar{K}]$ is the domain of the level of capital stocks where $\bar{K}$ is sufficiently large that feasible sequences of capital never exceed that value. There is such a $\bar{K}$ since there is diminishing returns to capital.

${ }^{23}$ In calendar time notation, given a sequence of lifetime utilities for all agents from even date $t\left\{\tilde{U}_{t}\right\}_{s=t}^{\infty}$, the sequence of offspring utilities is $\mathbf{U}=\left\{\tilde{U}_{t+2 s}\right\}_{s=0}^{\infty}$ and the continuation sequence is $\mathbf{U}^{\prime}=\left\{\tilde{U}_{t+2 s}\right\}_{s=1}^{\infty}$.

${ }^{24}$ See Stokey, Lucas, Jr., and Prescott (1989), Theorem 4.10.
} 
$k_{2}^{*}=h\left(k_{1}^{*}, \mathbf{U}_{1}\right), k_{3}^{*}=g\left(k_{2}^{*}, \mathbf{U}_{2}\right), k_{4}^{*}=h\left(k_{3}^{*}, \mathbf{U}_{2}\right)$, and so on. We then use $\left\{k_{t+1}^{*}\right\}$ together with (16) to compute the multiplier, $\lambda_{t+1}^{*}$,

$$
u^{\prime}\left(f\left(k_{t}^{*}\right)-k_{t+1}^{*}\right)=\left(\gamma+\lambda_{t+1}^{*}\right) f^{\prime}\left(k_{t+1}^{*}\right) u^{\prime}\left(f\left(k_{t+1}^{*}\right)-k_{t+2}^{*}\right),
$$

where $\lambda_{t+1}^{*}$ represents the multiplier on constraint (15) under $k=k_{t}^{*}$ and the particular utility sequence $\mathbf{U}$ that indexes the Pareto efficient allocation.

We are now ready to compute bequest wedge defined by (13) for a Pareto efficient allocation indexed by $\mathbf{U}$ :

$$
B W_{t}^{*}(\mathbf{U})=1-\left(\frac{u^{\prime}\left(c_{t}^{*}\right)}{\gamma u^{\prime}\left(c_{t+1}^{*}\right) f^{\prime}\left(k_{t+1}^{*}\right)}-\frac{\partial b_{t+2}\left(k_{t+1}^{*}, Q_{t+1}^{*}\right)}{\partial b_{t+1}} \frac{\left[-1+\frac{1}{\beta}\right]}{f^{\prime}\left(k_{t+1}^{*}\right)}\right),
$$

where $Q_{t+1}^{*}$ is generated from the Pareto efficient allocation as before and $\frac{\partial b_{t+2}\left(k_{t+1}^{*}, Q_{t+1}^{*}\right)}{\partial b_{t+1}}$ represents derivative of period $t+1$ offspring's policy with respect to the bequests received at $k_{t+1}^{*}$ and price sequence $Q_{t+1}^{*}$. Using $(18)$ in $B W_{t}^{*}(\mathbf{U})$ above gives

$$
B W_{t}^{*}(\mathbf{U})=-\frac{\lambda_{t+1}^{*}}{\gamma}+\frac{\partial b_{t+2}\left(k_{t+1}^{*}, Q_{t+1}^{*}\right)}{\partial b_{t+1}} \frac{\left[-1+\frac{1}{\beta}\right]}{f^{\prime}\left(k_{t+1}^{*}\right)} .
$$

The bequest wedge characterized by (19) has two components. First, consider the second term on the right-hand side of (19). This term represents the efficiency component of the bequest wedge that arises due to intergenertional disagreements. A comparison of this component with the Ramsey bequest wedge (14) shows that they are essentially identical. The efficiency component is positive, meaning it calls for a tax on bequests, as long as the offspring is impatient from the parent's perspective $(\beta<1)$. The intuition is the same as in the Ramsey case. In addition to the marginal physical return that the planner also faces, ' $f\left(k_{t+1}^{*}\right)$, in equilibrium the parent has an extra return to bequeathing because the offspring is undersaving from the parent's perspective. To allign parental equilibrium behavior with Pareto efficient bequest behavior, it is then efficient to create a wedge in the return to bequeathing. This efficient wedge is given by the second term on the right-hand side of (19). Observe that the sole reason for the efficiency component is the presence of disagreement: the wedge disappears when there is no disagreement $(\beta=1)$.

In the Ramsey case, the efficiency wedge is the only component of the wedge. In gen- 
eral, Pareto efficient bequest wedges have another component though. The first term on the right-hand side of (19) represents this component which comes from intergenerational redistribution. The intergenerational redistribution wedge is also present in the standard altruistic model of bequests without disagreements ${ }^{25}$ It is indeed easy to see from (19) that this component exists even when $\beta=1$. The intergenerational redistribution wedge is negative, and thus, calls for a marginal subsidy on bequests. It is strictly negative as long as the LaGrange multiplier, $\lambda_{t+1}^{*}$, is strictly positive. This is true as long as the constraint (15) binds which is equivalent to the planner putting a direct weight on the offspring born in period $t+1$. Intuitively, the offspring's welfare enters the planner's objective through two channles: one indirectly through the parent's welfare and the other directly. Thus, the planner cares about the offspring more than the parent does, and for this reason the parent bequeaths too little from planner's perspective. It is then optimal to subsidize the parents to make them bequeath enough. The magnitude of the intergenerational redistribution wedge is depends on the Pareto efficient allocation itself. In the formula in (19), this dependence is implicit as $\lambda_{t+1}^{*}$ depends on the sequence of utility promises, $\mathbf{U}$, which indexes Pareto efficient allocations.

Ramsey allocation as Pareto Improvement: An example with Log utility. By definition, the Ramsey allocation lies on the Pareto Frontier of our economy, that is, it is an efficient allocation. Another reason why Ramsey allocation and the taxes that achieve this allocation might be desirable is that the Ramsey allocation Pareto improves over laissez-faire market equilibrium allocation for a wide range of parameter values. In this section, we focus on an example where the instantaneous utility function is logarithmic and production in period $t$ is given by $f_{t}(k)=R_{t} k+w_{t}$. We derive a simple condition regarding when Ramsey allocation Pareto improves over laissez-faire equilibrium allocation that depends only on $\gamma, \delta$ and $\beta$. Using this condition, we prove that, if people are perfectly altruistic, then for any level of disagreement between parents and offspring, Ramsey allocation dominates the equilibrium allocation as altruism factor approaches one. Second, using numerical calculations, we find that, basically, for all reasonable values of these parameters, Ramsey allocation always Pareto dominates equilibrium allocation.

Proposition 9. The Ramsey allocation Pareto improves over laissez-faire market equilibrium allo-

\footnotetext{
${ }^{25}$ See Farhi and Werning (2010) and Kaplow (1995).
} 
cation if and only if

$$
\log \left(\frac{(1-\gamma \delta)(1+\gamma-\delta+\beta \delta)}{(1+\gamma)(1-\gamma \delta \beta-\delta+\beta \delta)}\right) A+\log (1-\delta+\beta \delta) B-\log (\beta) C \geq 0
$$

where

$$
\begin{array}{r}
A=1+\frac{\beta \delta}{1-\gamma \delta}(1+\gamma), \\
B=1+\frac{\beta \delta}{1-\gamma \delta}\left(\frac{1+\gamma}{1-\gamma \delta}+\gamma\right), \\
C=\frac{\beta \delta}{1-\gamma \delta}\left(\frac{1+\gamma}{1-\gamma \delta}\right) .
\end{array}
$$

Proof. Relegated to Appendix A.5.

We first use Proposition 9 to prove a limiting result: Ramsey allocation always dominates laissez-faire market equilibrium as $\gamma$ and $\delta$ converge to one. Below is a formal statement of this result.

Proposition 10. Suppose $\gamma=\delta$. Then, for any $\beta \in(0,1)$, Ramsey allocation Pareto improves over laissez-faire allocation as $\delta \rightarrow 1$.

Proof. Relegated to Appendix A.6.

Next, we are interested in the set of reasonable parameter values at which Ramsey allocation Pareto improves over laissez-fare equilibrium allocation. The table below gives the values of $\gamma=\delta$ above which Ramsey allocation dominates the equilibrium allocation for a given $\beta$.

\begin{tabular}{|c|c|c|c|c|c|}
\hline$\beta$ & 0.5 & 0.6 & 0.7 & 0.8 & 0.9 \\
\hline $\bar{\delta}$ & 0.758 & 0.745 & 0.734 & 0.724 & 0.718 \\
\hline
\end{tabular}

\subsection{Horizontal Redistribution: Progressivity of Bequest Taxation}

An important simplifying assumption we make so far in the paper is that all dynasties in the economy are identical. In this section, we relax this assumption and allow people to differ in their skill levels, which translates into income inequality in equilibrium.

A key issue that arises when the population is divided among different income groups is horizontal redistribution, that is, redistribution across different families. In this section, 
we incorporate Mirrlees (1971)'s model of horizontal redistribution into our intergenerational model and analyze how the normative predictions of the latter change under inequality and redistribution. First, we show that in two important cases all our normative results hold exactly. These are: (i) whenever redistribution can be performed via nondistortionary taxation (which correspond to the case where skills are publicly observable), and (ii) even if redistribution is limited by private information on the agents' level of skills, whenever we are interested in the Ramsey allocation of Section 4 , i.e., in the notation of Section 5.1, when $\lambda=0$. Second, we show that when the planner cares directly about the offspring's welfare (i.e., when $\lambda>0$ ) and, in addition, skills are private information to the agents, optimal bequest taxes are progressive.

To reduce the notational burden, we present the results with a three period framework. In order to analyze the efficient allocation allowing for imperfect horizontal distribution, we follow the Mirrleesian tradition assuming that labor income is publicly observable while agent's productivity is not. This assumption has an added bonus: whenever labor is supplied inelastically (e.g., because agents do not evaluate leisure as in our baseline model), horizontal redistribution is perfect and the planner is able to implement the same allocation as that with observable skills, which in turn corresponds to the allocation we studied so far in Section 4 and then extended in Section 5.1

Mirrleesian Model. Suppose the economy lasts three periods. At $t=0$ skill level $s \geq 0$ is drawn from a set $S$ according to a distribution $H$ and parents choose labour $l_{0} \in[0,1]$ with flow utility

$$
u\left(c_{0}\right)-v\left(l_{0}\right),
$$

where the function $v$ is increasing and convex, with $v^{\prime}(0)=0$ and $v^{\prime}(1)=\infty$. To simplify the analysis, we assume that in periods 1 and 2 labor is supplied inelastically at $\bar{l}_{t}=1$ as in the previous sections of the paper. Income in period $t=0$ equals $y_{0}=w_{0} s l_{0}$ which is publicly observable as is the real wage per unit of skill $w_{0}$. In periods $t=1,2$ all agents have a common labor income $y_{t}$, that is the offspring does not inherit the skill of their parents. This is an extreme form of mean reversion in skills, which will be somewhat important for the progressivity result.

We set $z_{t}(s):=u\left(c_{t}(s)\right)$ to be the utility level with the exclusion of disutility cost of labor. The planner cares directly about the offspring with welfare weight $\lambda$. Thus the plan- 
ner's objective function is:

$$
\max _{\left\{z_{t}(\cdot)\right\}_{t=0}^{2}, y_{0}(\cdot)} \int_{S}\left\{z_{0}(s)-v\left(\frac{y_{0}(s)}{w_{0} s}\right)+(\gamma+\lambda) z_{1}(s)+\delta(\gamma+\lambda \beta) z_{2}(s)\right\} d H(s) .
$$

For each $t=0,1,2$, define

$$
C_{t}:=\int_{S} c_{t}(s) d H=\int_{S} g\left(z_{t}(s)\right) d H, \quad L_{0}:=\int_{S} l_{0}(s) s d H, \quad L_{1}=L_{2}=1 \quad K_{t}:=\int_{S} k_{t}(s) d H
$$

where the function $g$ represents the inverse of the utility function $u$ (i.e., $g:=u^{-1}$ ) and the variables $C_{t}, L_{t}$ and $K_{t}$ represent the aggregate amounts of consumption, labor input in efficiency units, and capital in period $t$. As before, production factors are priced competitely, and in particular, $w_{t}:=F_{L}^{\prime}\left(K_{t}, L_{t}\right)$. Aggregate feasibility constraint is then given by, for each $t=0,1,2$,

$$
C_{t}+K_{t+1} \leq F\left(K_{t}, L_{t}\right)+(1-\theta) K_{t}, \quad \text { with } \quad K_{0} \text { given. }
$$

We indicate by $\mu_{t}$ the multiplier associated to the feasibility constraint in period $t$.

Finally, the planner also faces a set of incentive constraints in period zero, namely for all $s, \hat{s} \in S:$

$$
z_{0}(s)-v\left(\frac{y_{0}(s)}{s w_{0}}\right)+\gamma\left[z_{1}(s)+\delta z_{2}(s)\right] \geq z_{0}(\hat{s})-v\left(\frac{y_{0}(\hat{s})}{s w_{0}}\right)+\gamma\left[z_{1}(\hat{s})+\delta z_{2}(\hat{s})\right] .
$$

Notice that since all information about skill types is revelaed once and for all in period 0 , there are only period 0 incentive constraints.

Given $\lambda$, the planner's problem then is to maximize (21) subject to (22) and (23). By changing $\lambda \in[0, \infty)$, one can trace the whole set of Pareto efficient allocations. Therefore, $\lambda$ indexes Pareto efficient allocations.

Now, we characterize Pareto efficient allocations. For any $\lambda \geq 0$, consider the following perturbation of the corresponding Pareto efficient allocation: for a given $s$, set $z_{0}^{\varepsilon}(s)=$ $z_{0}^{*}(s)-\gamma \varepsilon, z_{1}^{\varepsilon}(s)=z_{1}^{*}(s)+\varepsilon$, and $z_{2}^{\varepsilon}(s)=z_{2}^{*}(s)$. Notice that since

$$
z_{0}^{\varepsilon}(s)+\gamma\left[z_{1}^{\varepsilon}(s)+\delta z_{2}^{\varepsilon}(s)\right]=z_{0}^{*}(s)+\gamma\left[z_{1}^{*}(s)+\delta z_{2}^{*}(s)\right],
$$

all such perturbations are by construction incentive compatible. This implies that for this 
set of perturbations, one can disregard the incentive constraint while solving the planner's problem. The efficient allocation has to solve the first-order optimality condition for the planner's problem over the choices of $\varepsilon$ in a neighbourhood of zero, i.e., the following condition has to hold:

$$
\lambda+\frac{\mu_{0} \gamma}{u^{\prime}\left(c_{0}^{*}(s)\right)}-\frac{\mu_{0}}{u^{\prime}\left(c_{1}^{*}(s)\right) R_{1}^{*}}=0,
$$

where $R_{1}^{*}:=F_{K}\left(K_{1}^{*}, 1\right)+(1-\theta)$. The above condition can be rearranged as:

$$
\frac{\lambda}{\mu_{0} \gamma} u^{\prime}\left(c_{0}^{*}(s)\right)=\frac{u^{\prime}\left(c_{0}^{*}(s)\right)}{\gamma R_{1}^{*} u^{\prime}\left(c_{1}^{*}(s)\right)}-1 .
$$

Recall that bequest wedge for a particular Pareto efficient allocation is the efficient wedge that the planner needs to create in order to make the parent choose that Pareto efficient allocation in equilibrium. Following the definition of the bequest wedge introduced by (13), we define bequest wedge for a family of type $s$ under Pareto index $\lambda$ to be:

$$
B W^{*}(\lambda, s)=1-\left(\frac{u^{\prime}\left(c_{0}^{*}(s)\right)}{\gamma R_{1}^{*} u^{\prime}\left(c_{1}^{*}(s)\right)}-\frac{\frac{\partial b_{2}\left(b_{1}^{*}, Q_{1}^{*}\right)}{\partial b_{1}}\left[-1+\frac{1}{\beta}\right]}{R_{1}^{*}}\right)
$$

(or using the taxation principle, this can be written in terms of parent's income $y_{0}$ ).

Plugging (24) in the bequest wedge definition above implies

$$
B W^{*}(\lambda, s)=-\frac{\lambda}{\mu_{0} \gamma} u^{\prime}\left(c_{0}^{*}(s)\right)+\frac{\frac{\partial b_{2}\left(b_{1}^{*}, Q_{1}^{*}\right)}{\partial b_{1}}\left[-1+\frac{1}{\beta}\right]}{R_{1}^{*}}
$$

Similar to the bequest wedge characterized by (19) in Section 5.1, the bequest wedge characterized by (25) has two components. The first component is due to intergenerational redistribution and always implies a subsidy on bequests whereas the second component is the correction due to intergenerational disagreements and always implies a tax.

There are two important cases in which the bequest wedge in (25) simplifies exactly to the bequest wedge formulas we studied earlier on. First, if productivity is observable, then even if we care about the offspring directly, $\lambda>0$, since we have $u^{\prime}\left(c_{0}^{*}(s)\right)=\mu_{0}$ for all s,

$$
B W^{*}(\lambda, s)=-\frac{\lambda}{\gamma}+\frac{\frac{\partial b_{2}\left(b_{1}^{*}, Q_{1}^{*}\right)}{\partial b_{1}}\left[-1+\frac{1}{\beta}\right]}{R_{1}^{*}} .
$$

This is the same as the expression for bequest wedge in Section 5.1. Under CEIS assump- 
tion, this expression does not depend on $s$. It is flat tax or subsidy depending on whether the disagreement correction or intergenerational redistribution component dominates. Intuitively, whenever labor income taxes are not distortionary, it is optimal to carry out all the horizontal redistribution using them and hence the intergenerational redistribution component of the bequest wedge is flax.

Second, if we only care about parent directly, $\lambda=0$, then the bequest wedge is the same as in Section 4 :

$$
B W^{*}(0, s)=\frac{\frac{\partial b_{2}\left(b_{1}^{*}, Q_{1}^{*}\right)}{\partial b_{1}}\left[-1+\frac{1}{\beta}\right]}{R_{1}^{*}}>0 .
$$

Under CEIS assumption, this calls for a flat bequest tax.

Now, we analyze thegeneral case where future generation is directly weighted in the planner's objective and skills are private information. It is straightforward to show that in this case $c_{0}^{*}(s)$ is increasing in $s$. This implies that the intergenerational redistribution wedge is decreasing in $s$, i.e. it calls for a decreasing (progressive) subsidy on bequests. The intuition for why this wedge is progressive can be found in Farhi and Werning (2010). Briefly, the incentive constraint is affected only according to the private altruistic factor $\gamma$, so the cost for the planner to generate some redistribution by reducing next generation consumption inequality is lower than generating re-distribution via generation $t=0$ consumption.

The fact that the intergenerational redistribution wedge is progressive implies that the bequest wedge is progressive under the CEIS assumption (since under CEIS the disagreement component is flat). Thus, depending on which component dominate, the bequest wedge either implies a subsidy that is decreasing with $s$ or a tax that is increasing. As we will see below, since bequests are also monotone increasing with $s$, this new force generates an element of progressivity in bequest taxation.

We now show that the efficient allocation can be implemented by inducing parents to bequest an amount to the kids that increases with $s$, subsiding savings of the kids and taxing or subsidizing bequests in a progressive way. Whether bequests are subsidized or taxed again depends on the level of the direct weight $\lambda$ the planner assigns to future generations (exactly as in Section 5.1). In the implementation exercise, parent's budget constraint is:

$$
c_{0}+b_{1}=R_{0} b_{0}+y_{0}-T^{b}\left(b_{1}\right)+T_{0}^{y}\left(y_{0}\right)
$$


where labor income taxes $T_{0}^{y}$ will be function of the parent's declaration and - by the taxation principle - can always be written in terms of the (observable) period zero income $y_{0}$. The function $T^{b}(\cdot)$ represents the bequest tax that is allowed to depend non-linearly on the level of bequests $b_{1}$ and for notational simplicity we assumed to be paid by the parent ${ }^{26}$ The offspring budget constraints are represented by

$$
\begin{aligned}
c_{1}+b_{2} & =R_{1}\left(1-\tau_{1}\left(y_{0}\right)\right) b_{1}+y_{1}+T_{1}^{y}\left(y_{0}\right) ; \\
c_{2} & =R_{2}\left(1-\tau_{2}\left(y_{0}\right)\right) b_{2}+y_{2}+T_{2}^{y}\left(y_{0}\right),
\end{aligned}
$$

where, for $t=1,2, \tau_{t}$, and $T_{t}^{y}$ represent wealth (or inheritance) taxes and labor income taxes, respectively. As indicated, both labor and wealth taxes are allowed to depend on the initial income level $y_{0}$ of the dynasty. ${ }^{27}$

Proposition 11. Assume $\beta<1$ and that $u$ is CEIS, then the set of proposed taxes on income $\left(T_{t}^{y}\right)$, bequest $\left(T^{b}\right)$, and wealth $\left(\tau_{t}\right)$ implement the Mirrlees allocation and: (i) if $\lambda=0$ the bequest tax function $T^{b}(\cdot)$ is linear in $b_{1}$; (ii) if $\lambda>0$ the bequest tax is progressive, i.e., $T^{b}(\cdot)$ is convex.

Proof. Relegated to Appendix A.7.

\subsection{Naivete}

In the main body of the paper, we assume that people are sophisticated in the sense that they are aware of the fact that their descendants disagree with them about how much to save for their old age. In this section, we analyze whether the optimality of transfer taxation depends on the assumption of sophistication. To do so, we assume that agents are naive, meaning that they believe (incorrectly) that their descendants fully agree with themselves regarding intertemporal allocation of resources. We focus on the Ramsey wedge but the results can be readily extended to other Pareto efficient allocations following the approach in Section 5.1. We show that even naive parents bequeath too much in equilibrium relative to the Ramsey level and, hence, it is optimal to tax parental transfers.

\footnotetext{
${ }^{26}$ As discussed in Farhi and Werning (2010), it is easy to see that for each of this tax we can set a tax on the offspring (inheritance tax) with the same characteristics.

${ }^{27}$ An alternative implementation strategy will involve non linear wealth taxes on the offspring. In this case, we will however lose the linearity of the offspring policy. A third implementation strategy involves wealth taxes (on offspring savings) that depend on the level of received bequests. In this last case, the link between bequest tax and wedge will be blurred.
} 
The problem of a naive parent in period $t$ is given by:

$$
\bar{V}\left(a_{t}, Q_{t}\right)=\max _{b_{t+1} \geq-B\left(Q_{t+1}\right)} u\left(c_{t}\right)+\gamma\left[u\left(\bar{c}_{t+1}\left(b_{t+1}, Q_{t+1}\right)\right)+\delta \bar{V}\left(\bar{a}_{t+2}\left(b_{t+1}, Q_{t+1}\right), Q_{t+2}\right)\right],
$$

subject to the budget constraints and the definition of wealth

$$
\begin{aligned}
c_{t} & =a_{t}-b_{t+1}, \\
\bar{c}_{t+1}\left(b_{t+1}, Q_{t+1}\right) & =R_{t+1} b_{t+1}+w_{t+1}-\bar{b}_{t+2}\left(b_{t+1}, Q_{t+1}\right), \\
\bar{a}_{t+2}\left(b_{t+1}, Q_{t+1}\right) & :=R_{t+2} \bar{b}_{t+2}\left(b_{t+1}, Q_{t+1}\right)+w_{t+2},
\end{aligned}
$$

together with the condition defining the policy of the offspring:

$$
\bar{b}_{t+2}\left(b_{t+1}, Q_{t+1}\right)=\arg _{\tilde{b}_{t+2} \geq-B\left(Q_{t+2}\right)} u\left(R_{t+1} b_{t+1}+w_{t+1}-\tilde{b}_{t+2}\right)+\delta \bar{V}\left(R_{t+2} \tilde{b}_{t+2}+w_{t+2}, Q_{t+2}\right) .
$$

Observe that this problem is identical to the problem of the sophisticated parent, (1), except that in the condition defining the policy of the offspring, (26), the offspring discounts future with $\delta$ instead of $\beta \delta$. This reflects the assumption that parents naively believe that their descendants are in full harmony with them regarding intertemporal preferences. We denote the naive parents' value function by $\bar{V}\left(a_{t}, Q_{t}\right)$. The naive value function gives the value of the solution to a standard dynamic programming problem with exponential discounters. It is well-known that since $u$ is concave, this value function is concave as well. Notice that the saving policy function of the offspring given in (26) is incorrect; it represents the naive belief of the parent about the saving policy of the offspring. To distinguish the parent's belief about the policy and the actual policy of the offspring in equilibrium, we denote the former by $\bar{b}_{t+2}(\cdot)$. Similarly, $\bar{c}_{t+1}(\cdot)$ and $\bar{a}_{t+2}(\cdot)$ refer to the naive belief of the parent about the offspring's period $t+1$ consumption and beginning of period $t+2$ wealth policies.

Now, we consider the true saving behavior of the offspring in equilibrium. The offspring solves

$$
\max _{\tilde{b}_{t+2} \geq-B\left(Q_{t+2}\right)} u\left(R_{t+1} b_{t+1}+w_{t+1}-\tilde{b}_{t+2}\right)+\beta \delta \bar{V}\left(R_{t+2} \tilde{b}_{t+2}+w_{t+2}, Q_{t+2}\right) .
$$

Observe that the naive offspring also faces the naive value function $\bar{V}$ since his naive beliefs about how his descendants will allocate consumption over time is in line with that of his 
parent.

We are now ready to establish the optimality of bequest tax. The parent naively believes that the offspring solves (26), and hence, the following first-order condition describes offspring saving behavior

$$
u^{\prime}\left(\bar{c}_{t+1}\left(b_{t+1}, Q_{t+1}\right)\right)=\delta R_{t+2} \bar{V}_{1}\left(\bar{a}_{t+2}\left(b_{t+1}, Q_{t+1}\right), Q_{t+2}\right) .
$$

Taking the first-order optimality condition with respect to bequests in the naive parent's problem and substituting (27) in, we find that the optimality condition for bequests in equilibrium is given by:

$$
u^{\prime}\left(c_{t}\right)=\gamma R_{t+1} u^{\prime}\left(\bar{c}_{t+1}\left(b_{t+1}, Q_{t+1}\right)\right)
$$

We therefore define the naive Ramsey bequest wedge as follows:

$$
\overline{B W}_{t}=1-\frac{u^{\prime}\left(c_{t}^{*}\right)}{\gamma R_{t+1}^{*} u^{\prime}\left(\bar{c}_{t+1}\left(b_{t+1}^{*}, Q_{t+1}^{*}\right)\right)}
$$

where, $\bar{c}_{t+1}\left(b_{t+1}^{*}, Q_{t+1}^{*}\right)$ corresponds to what the naive parent believes the offspring will choose if he receives $b_{t+1}^{*}$ as bequests and faces the price sequence implied by the Ramsey allocation, $Q_{t+1}^{*}$. We want to show that the naive bequest wedge is strictly positive, meaning given the Ramsey allocation, the naive parent would like to increase bequests. Remember that in the Ramsey allocation, we have

$$
-u^{\prime}\left(c_{t}^{*}\right)+\gamma R_{t+1}^{*} u^{\prime}\left(c_{t+1}^{*}\right)=0 .
$$

Pluggin this condition in the definition of the naive bequest wedge implies

$$
\overline{B W}_{t}=1-\frac{u^{\prime}\left(c_{t+1}^{*}\right)}{u^{\prime}\left(\bar{c}_{t+1}\left(b_{t+1}^{*}, Q_{t+1}^{*}\right)\right)} .
$$

Therefore, in order to establish the sign of $\overline{B W}_{t}$, we need to compare the Ramsey level of consumption of the offspring, $c_{t+1}^{*}$, with the parent's belief about how much the offspring will consume: $\bar{c}_{t+1}\left(b_{t+1}^{*}, Q_{t+1}^{*}\right)$.

Now, if the offspring chooses the Ramsey allocation in equilibrium, say thanks to the 
$\operatorname{tax} \tau_{t+2}^{*}$, then his first-order condition reads

$$
u^{\prime}\left(c_{t+1}^{*}\right)=\beta \delta R_{t+2}^{*}\left(1-\tau_{t+2}^{*}\right) \bar{V}_{1}\left(a_{t+2}^{*}, Q_{t+2}^{*}\right)
$$

The parent - on the other hand - believes the offspring will behave according to

$$
u^{\prime}\left(\bar{c}_{t+1}\left(b_{t+1}^{*}, Q_{t+1}^{*}\right)\right)=\delta R_{t+2}^{*}\left(1-\tau_{t+2}^{*}\right) \bar{V}_{1}\left(\bar{a}_{t+2}\left(b_{t+1}^{*}, Q_{t+1}^{*}\right), Q_{t+2}^{*}\right) .
$$

Concavity of $u$ and $\bar{V}$ then imply that

$$
\bar{c}_{t+1}\left(b_{t+1}^{*}, Q_{t+1}^{*}\right)<c_{t+1}^{*} .
$$

This ordering is intuitive: an agent with a lower discount factor, $\beta \delta$, tends to consume more in the current period than an agent with a higher discount factor, $\delta$, and the parent naively believes that the offspring has the higher discount factor. Therefore, we have the following result:

Proposition 12. Assume agents are naive and $\beta<1$, then the naive Ramsey bequest wedge is positive.

Therefore, we conclude that even when agents are naive, parents bequeath too much relative to the Ramsey level, and hence, it is optimal to tax bequests. The intuition for the bequest tax result when agents are naive is different from the case with sophisticated agents though. In the naive case, parents bequeath too much relative to the Ramsey level not because they want to compensate for their offspring's undersavings but because their perceived marginal return to bequeathing, $u^{\prime}\left(\bar{c}_{t+1}\left(b_{t+1}^{*}, Q_{t+1}^{*}\right)\right)$, is larger than the actual marginal return, $u^{\prime}\left(c_{t+1}^{*}\right)$. One can further show that, if we restrict attention to linear equilibria, then we can implement the Ramsey allocation via taxes, and the optimal tax on bequests is given by the naive bequest wedge in (28).

\subsection{Longer Life Cycle, Coexistence, and Inter Vivos Taxation}

We assume that people live for two periods in our benchmark model. In this section, we extend our model by allowing each agent within a dynasty to be active for $I+1$ periods: in the first $I$ periods, agents make consumption saving decisions. In the last period of their lives, parents coexist with their offspring who are already in the first period of young adulthood. Parents decide how much to consume and transfer to their offspring. Transfers can 
be made in two ways: inter vivos transfers are received by the offspring during the coexistence period, and bequests are received at the beginning of the next period, after the parent dies. We show that the longer life cycle does not alter the main result, that is, bequests should be taxed. Furthermore, thanks to the coexistence period in the extended model, we are able to analyze parental inter vivos transfer behavior and establish the optimality of taxing inter vivos transfers as well.

Consider any calendar year $t$ in which there is a parent who is in the last period of his life. His preference over dynastic allocation is given by

$$
V_{t}=u\left(c_{t}^{o}\right)+\gamma\left[u\left(c_{t}\right)+\delta u\left(c_{t+1}\right)+. .+\delta^{I-1} u\left(c_{t+I-1}\right)+\delta^{I} V_{t+I}\right],
$$

where $V_{t}$ represents the dynastic welfare of the parent who is in the last period of his life in period $t$ and $V_{t+I}$ represents that of the offspring in his terminal period, $t+I$. The term $c_{t}^{o}$ is the last period consumption of the parent and $c_{t}$ is the consumption level of the offspring who is at age 1 in period $t$. Observe that $c_{t}^{o}$ and $c_{t}$ occur in the same period. To keep aggregate labor supply constant across periods, we assume that only the offspring has one unit of time endowment in the period of coexistence. Clearly, this assumption is not material for any of our results.

There are two 'natural' ways to extent our baseline model to a multi-period setup. They both deliver the same qualitative predictions. First, one can envision agents as standard exponential discounters, perhaps with varying discount factors over the life cycle so that the discount factor between own consumption at age $i$ and $i+1$ is $\beta_{i} \delta \leq \delta$. In this formulation, agents are time-consistent. Second, we can assume that agents face self-control problems and have time-inconsistent preferences. In this model, agents disagree with their future selves over intertemporal trade offs. That is, at any age $i$, people discount future with $\beta_{i} \delta$ and want their future selves to discount with $\delta$.

The time-consistent extension of the baseline model behaves quite similarly with the baseline model because in both models the only source of disagreement is the one that exists between different generations. Therefore, it is somewhat easier to see that the main results continue to hold in this extension. That is, as long as offspring are impatient from parents' perspective in the period they receive transfers, it is optimal to tax parental transfers. This extension allows us to see that inter vivos as well as bequests should be taxed ${ }^{28}$

\footnotetext{
${ }^{28}$ One might argue that since inter vivos are received while the parent is still alive, the parent might have more leverage in affecting offspring saving behavior in that period. If the parent is able to ensure that the off-
} 
Instead, in the rest of the section, we focus on the time-inconsistent extension where, in addition to intergenerational disagreement, people disagree with their future selves as well. We find that our results survive this double degree of disagreement as well.

We model time-inconsistent behavior following Laibson(1997)'s quasi-hyperbolic framework. The offspring's preference in period $i$ of his life is

$$
\begin{gathered}
u\left(c_{t+i-1}\right)+\beta_{i} \delta\left[\sum_{j=i+1}^{I} \delta^{j-(i+1)} u\left(c_{t+j-1}\right)+\delta^{I-i} V_{t+I}\right], \text { for } 1 \leq i \leq I-1 \\
u\left(c_{t+I-1}\right)+\beta_{I} \delta V_{t+I}
\end{gathered}
$$

When $\beta_{i}=1$ for all $i$, people are fully time-consistent at all ages; there is no present-bias problem. Whenever $\beta_{i}<1$ for some $i$, people face present-bias problems at age $i$. Observe that we are extending the hyperbolic discounting model by allowing for the existence (and severity) of the present-bias problem, $\beta_{i}$, to depend on age 29 We extend the standard model of present-bias in order to show that our transfer taxation results do not depend on how the degree of present-bias evolves over the life cycle. As we will see, the only assumption needed in order to establish optimality of transfer taxation is that the offspring has a present-bias problem in the period he receives the transfer.

Let $d_{t}$ and $b_{t+1}^{o}$ denote the inter vivos transfers and bequests made by the parent who is in his last period of life in period $t$. Let $b_{t+i}$ denote the offspring's age $i$ saving level.

The parent, whose wealth level is $a_{t}=R_{t} b_{t}+w_{t}$, solves

$$
V\left(a_{t}, Q_{t}\right)=\max _{b_{t+1}^{o}, d_{t}} u\left(c_{t}^{o}\right)+\gamma\left[\sum_{i=0}^{I-1} \delta^{i} u\left(c_{t+i}\right)+\delta^{I} V\left(a_{t+I}, Q_{t+I}\right)\right],
$$

spring saves exactly according to parental preference, then they would not have a reason to do excessive inter vivos transfers, and hence, there would be no need to tax inter vivos transfers. The "Rotten Kid Theorem" of Becker (1974) would be reestablished in that case.

${ }^{29}$ If we were to take $\beta_{i}=\beta$ for all $i$, as previous papers have assumed, that would mean that the degree of present-bias problem is constant as people age, and all our results hold in this special case. 
subject to the budget constraints 30

$$
\begin{aligned}
c_{t}^{o} & =R_{t} b_{t}-b_{t+1}^{o}-d_{t} \\
c_{t}\left(d_{t}, Q_{t}\right) & =d_{t}+w_{t}-b_{t+1}\left(d_{t}, Q_{t}\right), \\
c_{t+1}\left(d_{t}, b_{t+1}^{o}, Q_{t}\right) & =R_{t+1} b_{t+1}\left(d_{t}, Q_{t}\right)+w_{t+1}+R_{t+1} b_{t+1}^{o}-b_{t+2}\left(d_{t}, b_{t+1}^{o}, Q_{t}\right), \\
c_{t+i-1}\left(d_{t}, b_{t+1}^{o}, Q_{t}\right) & =R_{t+i-1} b_{t+i-1}\left(d_{t}, b_{t+1}^{o}, Q_{t}\right)+w_{t+i-1}-b_{t+i}\left(d_{t}, b_{t+1}^{o}, Q_{t}\right), \text { for } 3 \leq i \leq I, \\
a_{t+I}\left(d_{t}, b_{t+1}^{o}, Q_{t}\right) & =R_{t+I} b_{t+I}\left(d_{t}, b_{t+1}^{o}, Q_{t}\right),
\end{aligned}
$$

and subject to the constraints defining the policy functions of future selves: 31

$$
\begin{aligned}
& b_{t+1}\left(d_{t}, Q_{t}\right)=\arg \max u\left(c_{t}\right)+\beta_{1} \delta\left[u\left(c_{t+1}\right)+\ldots+\delta^{I-1} u\left(c_{t+I-1}\right)+\delta^{I} V\left(a_{t+I}, Q_{t+I}\right)\right] \\
& \text { s.t. } \\
& b_{t+2}\left(d_{t}, b_{t+1}^{o}, Q_{t}\right)=\arg \max u\left(c_{t+1}\right)+\beta_{2} \delta\left[u\left(c_{t+2}\right)+\ldots+\delta^{I-2} u\left(c_{t+I-1}\right)+\delta^{I-1} V\left(a_{t+I}, Q_{t+I}\right)\right] \\
& \text { s.t. } \\
& \text {... } \\
& \text { s.t. } \\
& b_{t+I-1}\left(d_{t}, b_{t+1}^{o}, Q_{t}\right)=\arg \max u\left(c_{t+I-2}\right)+\beta_{I-1} \delta\left[u\left(c_{t+I-1}\right)+\delta V\left(a_{t+I}, Q_{t+I}\right)\right] \\
& \text { s.t } \\
& \left.b_{t+I}\left(d_{t}, b_{t+1}^{o}, Q_{t}\right)=\arg \max u\left(c_{t+I-1}\right)+\beta_{I} \delta V\left(a_{t+I}, Q_{t+I}\right)\right) \text {. }
\end{aligned}
$$

To better understand the notation and the nature of policy functions in the planning problem, first observe that when an agent of age $i$ in calendar year $t+i-1$ is deciding $b_{t+i}$, he sees the direct effect of his choice on the next period self's saving choice. Clearly, agent $i$ 's saving choice indirectly affects his saving at age $n>i, b_{t+n}$, since $b_{t+i}$ choice affects $b_{t+i+1}$ choice, which then affects $b_{t+i+2}$ choice, and so on. The dependence of $b_{t+n}$ on $b_{t+i}$

\footnotetext{
${ }^{30}$ The real interest and wage rates are given by marginal products of capital and labor as in the benchmark model. The only difference is for the period right after coexistence, total capital stock in the economy is equal to the sum of the offspring's savings in the coexistence period and parental bequests

$$
k_{t}=b_{t+1}+b_{t+1}^{o} .
$$

${ }^{31}$ Again, the notation implicitly assumes policies are single valued. The usual caveat applies: whenever we have multiple solutions, the policies should be interpreted as selections from the policy correspondences.
} 
can be described by a (nested) function $b_{t+n}\left(b_{t+n-1}\left(\ldots b_{t+i+1}\left(b_{t+i}, Q_{t+i}\right) \ldots\right), Q_{t+n-1}\right)$. Without creating a confusion, we can denote it as a single function of only $\left(b_{t+i}, Q_{t+i}\right)$. Going backwards, the 'initial' choices in our recursion are $d_{t}$ and $b_{t+1}^{o}$. As a consequence, the vector of functions $\left[b_{t+1}\left(d_{t}, Q_{t}\right), b_{t+2}\left(d_{t}, b_{t+1}^{o}, Q_{t}\right) \ldots, b_{t+I}\left(d_{t}, b_{t+1}^{o}, Q_{t}\right)\right]$ denote the functions that describe how the offspring's savings choices over the life cycle depend on parental transfers they receive, $\left(d_{t}, b_{t+1}^{o}\right)$. Observe that offspring's saving at age 1 in year $t$, denoted by $b_{t+1}$, only depends on inter vivos transfers she receives in that period but not on the level of bequests, $b_{t+1}^{o}$, since we assume that these people receive bequests only after their parents die, in year $t+1$.

We now derive a marginal condition that characterizes equilibrium inter vivos behavior assuming differentiability of the policy functions that describe offspring saving behavior at different ages.

Consider a parent's problem under laissez-faire of choosing $d_{t}$ and $b_{t+1}^{o}$ subject to the flow budget constraints and the offspring's policy functions. Let $\frac{\partial b_{t+i}\left(d_{t}, b_{t+1}^{0}, Q_{t}\right)}{\partial d_{t}}$ represent how an increase in inter vivos transfers affects savings at age $i$ calendar year $t+i-1$. For notational simplicity, we will write this partial derivative as $\frac{\partial b_{t+i}}{\partial d_{t}}$ whenever doing so does not create a confusion. The parent's first-order optimality condition with respect to the inter vivos decision is

$$
u^{\prime}\left(c_{t}^{o}\right)=\gamma\left(u^{\prime}\left(c_{t}\right)\left[1-\frac{\partial b_{t+1}}{\partial d_{t}}\right]+\sum_{i=1}^{I-1} \delta^{i-1} u^{\prime}\left(c_{t+i}\right) \frac{\partial c_{t+i}}{\partial d_{t}}+\delta^{I} V_{1}\left(a_{t+I}, Q_{t+I}\right) R_{t+I} \frac{\partial b_{t+I}}{\partial d_{t}}\right)
$$

where

$$
\frac{\partial c_{t+i}}{\partial d_{t}}=\left[R_{t+i} \frac{\partial b_{t+i}}{\partial d_{t}}-\frac{\partial b_{t+i+1}}{\partial d_{t}}\right]
$$

and, clearly, the derivatives are evaluated at the equilibrium allocation and prices. Consider the problem of the offspring in the first period of his adult life, in period $t$. When choosing his level of savings, $b_{t+1}$, this agent faces the policy functions $\left(b_{t+2}\left(b_{t+1}\right), \ldots, b_{t+I}\left(b_{t+1}\right)\right)$. Taking first-order condition for his period $t$ saving, we get

$$
u^{\prime}\left(c_{t}\right)=\beta_{1} \delta\left\{\sum_{i=1}^{I-1} \delta^{i-1} u^{\prime}\left(c_{t+i}\right) \frac{\partial c_{t+i}}{\partial b_{t+1}}+\delta^{I-1} V_{1}\left(a_{t+I}, Q_{t+I}\right) R_{t+I} \frac{\partial b_{t+I}}{\partial b_{t+1}}\right\}
$$

where, again, the derivatives are evaluated at the equilibrium allocation and prices. Using 
(31) in parental optimality condition for inter vivos, 29), and the fact that the only way $d_{t}$ affects decisions from $t+1$ onward is through its effect on period $t$ decisions, meaning

$$
\frac{\partial b_{t+i}}{\partial d_{t}}=\frac{\partial b_{t+i}}{\partial b_{t+1}} \frac{\partial b_{t+1}}{\partial d_{t}}
$$

we get the following proposition which describes equilibrium parental inter vivos behavior under differentiability of policy functions.

Proposition 13. Suppose the policy functions that describe offspring behavior over the life cycle are differentiable. The equilibrium inter vivos behavior is characterized by

$$
u^{\prime}\left(c_{t}^{o}\right)=\gamma\left(u^{\prime}\left(c_{t}\right)+\frac{\partial b_{t+1}\left(d_{t}, Q_{t}\right)}{\partial d_{t}} u^{\prime}\left(c_{t}\right)\left\{-1+\frac{1}{\beta_{1}}\right\}\right) .
$$

Condition (32) is analogous to (10), the optimality condition for bequests in the benchmark model under differentiability. The left-hand side is the marginal cost of increasing inter vivos transfers, which equals the utility loss from forgone parental consumption. The first term on the right-hand side is the usual marginal benefit of increasing saving - the utility gain from increased consumption in the period during which returns to savings are received. The second term on the right-hand side summarizes how increasing inter vivos transfers affects parental welfare by affecting future consumption levels of the offspring. As long as $\beta_{1}<1$, meaning that the offspring faces present-bias problems in his first period of life, this term is positive: there is an additional marginal benefit of increasing transfers for the parent. Intuitively, the parent, being fully sophisticated, knows that from his perspective, self 1 is undersaving. So, parental welfare increases if the parent can make self 1 increase period 1 savings, which is possible by increasing inter vivos transfers since $\frac{\partial b_{t+1}\left(d_{t}\right)}{\partial d_{t}}>0$.

To see the implication of Proposition 13 for Ramsey inter vivos taxation, first observe that in the Ramsey allocation we have

$$
u^{\prime}\left(c_{t}^{o *}\right)=\gamma u^{\prime}\left(c_{t}^{*}\right) .
$$

Now define the Ramsey inter vivos wedge as:

$$
I W_{t}^{*}=-u^{\prime}\left(c_{t}^{o *}\right)+\gamma\left(u^{\prime}\left(c_{t}^{*}\right)+\frac{\partial b_{t+1}\left(d_{t}^{*}, Q_{t}^{*}\right)}{\partial d_{t}} u^{\prime}\left(c_{t}^{*}\right)\left\{-1+\frac{1}{\beta_{1}}\right\}\right) .
$$


The Ramsey inter vivos wedge in period $t$ measures the distortion that the planner needs to create in the inter vivos decision of a parent in that period in order to make him choose the Ramsey level of inter vivos transfers. A positive (negative) $I W_{t}$ means that a parent would like to increase (decrease) his inter vivos transfers marginally above (below) the Ramsey level if there is no government intervention.

Corollary 14. Suppose the policy functions that describe offspring behavior over the life cycle are differentiable. Then, $I W_{t}^{*}>0$ for all parenthood periods $t$.

Proof. Follows directly from 33 , the definition of $I W_{t}^{*}$, and that $\frac{\partial b_{t+1}\left(d_{t}^{*}, Q_{t}^{*}\right)}{\partial d_{t}}>0$, which follows from Lemma 16 in the Appendix.

Corollary 14 , which is analogous to Corollary 5 for the case of bequests in the main text, establishes that parents would increase their inter vivos transfers above the Ramsey level if there is no government intervention. One can further show that an analog to Proposition 6 also holds for the environment with multiperiod life cycle and coexistence: under the assumption that (Markov) equilibrium (with linear taxes) optimal policies are linear in current wealth, there is a linear tax system that implements the Ramsey allocation, and in this tax system, taxes on inter vivos is strictly positive.

The argument for positive bequest taxation in a multiperiod life-cycle environment is identical to the case for inter vivos taxation and therefore will be omitted for the sake of brevity. One can show optimality of bequest taxation by plugging the first-order optimality condition of offspring for period 2 savings, $b_{t+2}$, into the first-order optimality condition of bequests.

\subsection{Long-Term Assets and Liquidity Constraints}

The front-loading of consumption by offspring relative to what their parents prefer lies at the heart of our transfer taxation results. A natural question then is: if the parents have access to assets with more than one-period maturities, can they force their offspring into the consumption patterns they want by carefully choosing the portfolio of these assets? This is an important question because, if they can, then there would be no disagreement in saving behavior from parent's perspective. That would imply that the disagreement wedge disappears which then would imply there is no need to tax transfers.

First, observe that if the offspring are not liquidity constrained, meaning that they can borrow as much as they want within their natural borrowing limits, then the timing of 
transfers cannot constrain their consumption patterns at all. In this case, the strategy of using long-term assets is fruitless in disciplining offspring's saving behavior, and we are back at the benchmark environment without long-term assets: both bequests and inter vivos transfers should be taxed ${ }^{32}$ The real question, then, is what happens if parents have access to long-term assets and children face liquidity constraints? This is the question we pick up in this section. To sum up, we find that, as long as the parents do not have access to a portfolio of assets that allow them to target transfers to each and every period of the offspring's life cycle, transfer taxation remains to be optimal.

We use the multi-period environment laid out in Section 5.4 for our analysis. To make things simple, suppose people are not allowed to borrow at all. Suppose that in addition to inter vivos transfers and bequests, parents can use an illiquid asset to transfer resources directly to period $t+2$. Let $b_{t+2}^{o}$ denote the amount of this illiquid bequest where the subscript refers to the period in which the child receives the bequest. Suppose the return to this asset is $R_{t+1} R_{t+2}$. The budget constraints then are:

$$
\begin{aligned}
c_{t}^{o} & =R_{t} b_{t}-d_{t}-b_{t+1}^{o}-b_{t+2}^{o}, \\
c_{t} & =d_{t}+w_{t}-b_{t+1}, \\
c_{t+1} & =R_{t+1} b_{t+1}+w_{t+1}+R_{t+1} b_{t+1}^{o}-b_{t+2}, \\
c_{t+2} & =R_{t+2} b_{t+2}+w_{t+2}+R_{t+1} R_{t+2} b_{t+2}^{o}-b_{t+3}, \\
c_{t+i-1} & =R_{t+i-1} b_{t+i-1}+w_{t+i-1}-b_{t+i}, \text { for } 4 \leq i \leq I .
\end{aligned}
$$

Let $\left[b_{t+1}\left(d_{t}\right), b_{t+2}\left(d_{t}, b_{t+1}^{o}, b_{t+2}^{o}\right) \ldots, b_{t+I}\left(d_{t}, b_{t+1}^{o}, b_{t+2}^{o}\right)\right]$ denote the functions that describe how the offspring's savings choices over the life cycle depend on parental transfers they receive, where we simplified notation by ignoring the dependence on the sequence of prices 33

For the sake of argument, suppose that people do not have any labor income, meaning $w_{t}=0$ for all $t$. In this case, one can show that parents use the transfers to keep offspring borrowing constrained in periods $t$ and $t+1$. The intuition is simple. Suppose the offspring is not constrained in period $t$ in equilibrium. This means his optimal saving level $b_{t+1}$ is given by (31). Now, if the parent increases his bequests and decreases his inter vivos transfers in a way that keeps the total amount of transfers unchanged, the child will have

\footnotetext{
${ }^{32}$ For a formal analysis of this claim, see Pavoni and Yazici (2012) section 11.E.

${ }^{33}$ Notice that a change in illiquid bequests affects the offspring's saving decisions in periods $t+1$ and $t+2$, but not his saving decision in period $t$. This is due to our assumption that children learn the levels of both liquid and illiquid bequests in period $t$, after they make their period $t$ savings decision.
} 
to decrease his period $t$ savings to keep his preferred allocation. If the parent continues to backload transfers, there will be a point at which the child will deplete his savings completely and will become borrowing constrained. From this point onward, backloading of transfers strictly increases parental welfare, and the parent does this until the equilibrium saving behavior of the offspring is exactly in line with that of the parent:

$$
u^{\prime}\left(c_{t}\right)=\delta\left\{\sum_{i=1}^{I-1} \delta^{i-1} u^{\prime}\left(c_{t+i}\right) \frac{\partial c_{t+i}}{\partial b_{t+1}}+\delta^{I-1} V_{1}\left(a_{t+I}, Q_{t+I}\right) R_{t+I} \frac{\partial b_{t+I}}{\partial b_{t+1}}\right\}
$$

where the term $\frac{\partial c_{t+i}}{\partial b_{t+1}}$ is defined analogous to 30 . Similarly, the parent will use liquid and illiquid bequests to align offspring saving behavior with his own in period $t+1$ :

$$
u^{\prime}\left(c_{t+1}\right)=\delta\left\{\sum_{i=2}^{I-1} \delta^{i-2} u^{\prime}\left(c_{t+i}\right) \frac{\partial c_{t+i}}{\partial b_{t+2}}+\delta^{I-2} V_{1}\left(a_{t+I}, Q_{t+I}\right) R_{t+I} \frac{\partial b_{t+I}}{\partial b_{t+2}}\right\}
$$

This implies that the parent does not have a motive to transfer too much and hence there is no need to distort transfers. For inter vivos transfers, this can be seen by plugging (34) into the parental optimality condition for inter vivos transfers, equation (29). For bequests, it can be shown by plugging (35) into the parental optimality condition for bequests.

We now argue that even in this case, it is optimal to tax parental transfers: not inter vivos or bequests but illiquid bequests. Notice that the parent does not have a long-term asset that pays in period $t+3$. As a result, the offspring will save according to his presentbias problem in period $t+2$ and choose $b_{t+3}$ to satisfy

$$
u^{\prime}\left(c_{t+2}\right)=\beta_{3} \delta\left\{\sum_{i=3}^{I-1} \delta^{i-3} u^{\prime}\left(c_{t+i}\right) \frac{\partial c_{t+i}}{\partial b_{t+3}}+\delta^{I-3} V_{1}\left(a_{t+I}, Q_{t+I}\right) R_{t+I} \frac{\partial b_{t+I}}{\partial b_{t+3}}\right\} .
$$

Plugging (34), (35), and (36), in the parent's optimality condition regarding illiquid bequests, we get: 34

$$
u^{\prime}\left(c_{t}^{o}\right)=\gamma\left(R_{t+1} R_{t+2} \delta^{2} u^{\prime}\left(c_{t+2}\right)+\frac{\partial b_{t+3}}{\partial b_{t+2}^{o}} \delta u^{\prime}\left(c_{t+2}\right)\left[-1+\frac{1}{\beta_{3}}\right]\right) .
$$

The second term on the right-hand side is positive, which means that parents do too much illiquid bequeathing and therefore should be taxed.

\footnotetext{
${ }^{34}$ For an exact derivation of 37 , see Appendix A.8.
} 
Intuitively, since the parent cannot transfer resources to period $t+3$ (the fourth period of the offspring's life) directly, there is no way to discipline period $t+2$ savings of the offspring via the timing of transfers. Therefore, the parent still bequests too much, this time through the illiquid asset, and hence, the optimal tax on illiquid bequests is positive. If there were a perfect set of long-term assets, $\left\{b_{t+i}^{o}\right\}_{i=1}^{I}$, available to the parent, only in that case would the parent be able to control the offspring's consumption completely and would not need to transfer too much relative to the Ramsey allocation through any of these assets. Only in that case would the optimality of transfer taxation break 35

\section{Conclusion}

We study optimal taxation of parental transfers in a model where altruistic parents and their offspring disagree on intertemporal trade-offs. We prove that laissez-faire equilibrium is inefficient in a Pareto sense due to disagreement. We focus on the Ramsey allocation, the allocation that maximizes the welfare of the initial parent, as our benchmark Pareto efficient allocation. We show that, if offspring are impatient from parents' perspective, then parents bequeath too much relative to Ramsey level, and hence, it is optimal to tax bequests. We then consider policies that target any point on the Pareto frontier of the economy. We find that intergenerational disagreement again call for a taxation of bequests. In this case, there is another component of bequest taxation which comes from intergenerational redistribution and this component always asks for a subsidy on bequests. The sign of the tax depends on which component dominates. We also consider an economy with income inequality across families in which government wants to redistribute from the rich to the poor. We find that if labor income taxes are distortionary and society puts direct weight on future agents, then bequest taxes are progressive.

Finally, we show that the optimality of positive taxes on transfers remains valid even when (i) we consider life cycles with arbitrarily long finite horizons, (ii) when parents can

\footnotetext{
${ }^{35}$ Remember that we assumed that the offspring have no labor income of their own, which - together with the no borrowing constraint - allowed parents to control the levels of the first two periods of consumption. When offspring receive labor income over their life cycle, then, depending on the shape of the wage profile over the life cycle, it might not be possible for parents to drive children to behave according to the Euler equations (34) and (35) even if parents have access to a perfect portfolio of assets. Alternatively, if the borrowing limits are not exactly zero but allow for some undersaving behavior for the offspring, then, depending on the wage profile over the life cycle, again parents may not be able to arrange children's first and second period consumption according to (34) and (35). In these cases, parents will have motives to transfer too much through inter vivos and liquid bequests, and the optimal taxes on these transfers should again be positive.
} 
trade long maturity assets, and (iii) when parents are naive in the sense that they do not realize the existence of intergenerational disagreements.

\section{References}

Becker, G. S. (1974): “A Theory of Social Interactions," Journal of Political Economy, 82(6), 1063-93.

BERNHEIM, B. D. (1989): “Intergenerational Altruism, Dynastic Equilibria and Social Welfare," The Review of Economic Studies, 56(1), pp. 119-128.

Clarke, E. J., M. Preston, J. Raksin, and V. L. Bengtson (1999): “Types of Conflicts and Tensions Between Older Parents and Adult Children," The Gerontologist, 39(3), pp. 261-270.

Cremer, H., And P. Pestieau (2010): "Wealth and Wealth Transfer Taxation: A Survey," International Studies Program Working Paper 10-17, Andrew Young School of Policy Studies.

DellaVigna, S., And U. Malmendier (2004): "Contract Design and Self-control: Theory and Evidence," The Quarterly Journal of Economics, 119(2), 353-402.

DoepKe, M., And M. Tertilt (2009): “Women's Liberation: What's in It for Men?,” The Quarterly Journal of Economics, 124(4), 1541-1591.

DoePKe, M., AND F. ZILIBOtTI (2014): "Parenting with style: altruism and paternalism in intergenerational preference transmission," UBSCENTER - Working Papers 008, UBS International Center of Economics in Society - Department of Economics - University of Zurich.

FARHI, E., AND I. WeRning (2010): "Progressive Estate Taxation," The Quarterly Journal of Economics, 125(2), 635-673.

Gruber, J., And B. Koszegi (2004): "Tax incidence when individuals are timeinconsistent: the case of cigarette excise taxes," Journal of Public Economics, 88(9-10), 19591987.

HARRIS, C. J., AND D. LAibSON (2001): “Dynamic Choices of Hyperbolic Consumers," Econometrica, 69(4), 935-957.

- (2002): "Hyperbolic Discounting and Consumption," in Advances in Economics and Econometrics: Theory and Applications, Eighth World Congress, ed. by M. Dewatripont, L. P. Hansen, and S. Turnovsky, vol. 1, pp. 258-298. Cambridge: Cambridge University Press. 
Jacobson, D. B., B. G. RAUb, AND B. W. Johnson (2007): “The Estate Tax: Ninety Years and Counting," Discussion paper, Internal Revenue Service, U.S. Department of the Treasury.

KAPLOW, L. (1995): “A Note on Subsidizing Gifts," Journal of Public Economics, 58(3), 469477.

(2001): “A Framework for Assessing Estate and Gift Taxation," in Rethinking Estate and Gift Taxation, ed. by W. Gale, J. Hines, and J. Slemrod. Brookings Institution Press.

Kocherlakota, N. R. (2005): "Zero Expected Wealth Taxes: A Mirrlees Approach to Dynamic Optimal Taxation," Econometrica, 73(5), 1587-1621.

KopCZUK, W. (2010): “Economics of Estate Taxation: A Brief Review of Theory and Evidence," NBER Working Paper 15741, National Bureau of Economic Research.

Krusell, P., B. Kuruscu, AND A. J. Smith (2010): “Temptation and Taxation," Econometrica, 78(6), 2063-2084.

Krusell, P., And A. A. Smith (2003): “Consumption-Savings Decisions with QuasiGeometric Discounting," Econometrica, 71(1), 365-375.

LAIBSON, D. (1994): “Self-Control and Saving," Discussion paper.

(1997): “Golden Eggs and Hyperbolic Discounting," The Quarterly Journal of Economics, 112(2), 443-477.

Laibson, D., A. Repetto, and J. Tobacman (2007): “Estimating Discount Functions with Consumption Choices over the Lifecycle," NBER Working Paper 13314, National Bureau of Economic Research.

LAITNER, J. (1997): "Intergenerational and Interhousehold Economic Links," in Handbook of Population and Family Economics, ed. by M. R. Rosenzweig, and O. Stark, vol. 1. New York: Elsevier/North Holland.

MirRleEs, J. A. (1971): “An Exploration in the Theory of Optimum Income Taxation," Review of Economic Studies, 38(114), 175-208.

Montrucchio, L., AND N. PAVONI (2010): “Dynamic Contracts, Recursive Formulations, and Envelope Theorems," Discussion paper.

Morris, S., AND A. POstlewaite (1997): “Observational Implications of NonExponential Discounting," Discussion paper. 
O'Donoghue, T., And M. Rabin (1999): "Doing It Now or Later," American Economic Review, 89(1), 103-124.

_ (2003): "Studying Optimal Paternalism, Illustrated by a Model of Sin Taxes," American Economic Review, 93(2), 186-191.

(2006): “Optimal Sin Taxes," Journal of Public Economics, 90(10-11), 1825-1849.

Pavoni, N., And H. YaZici (2012): “Optimal Life-cycle Capital Taxation under SelfControl Problems," IGIER Working Paper 467, IGIER.

Phelps, E. S., AND R. A. PollaK (1968): “On Second-Best National Saving and GameEquilibrium Growth," The Review of Economic Studies, 35(2), 185-199.

Piketty, T., AND E. SAez (2013): “A Theory of Optimal Inheritance Taxation," Econometrica, forthcoming.

Stokey, N. L., R. E. LuCAs, JR., And E. C. Prescott (1989): Recursive Methods in Economic Dynamics. Harvard University Press, Cambridge, MA.

StrotZ, R. H. (1955): "Myopia and Inconsistency in Dynamic Utility Maximization," The Review of Economic Studies, 23(3), 165-180. 


\section{A Appendix: Proofs}

\section{A.1 Proof of Proposition 1}

Before starting the proof, we demonstrate two preliminary lemmas which we use in the proof later on. To simplify notation, we suppress the dependence of the policy function, $b_{t+2}$, on the price sequence, $Q_{t+1}$.

Lemma 15. The policy of the offspring $b_{t+2}(\cdot)$ is increasing in the amount of bequests received and the value function $V\left(\cdot, Q_{t}\right)$ is strictly increasing in wealth.

Proof. It is easy to see that $V\left(\cdot, Q_{t}\right)$ is strictly increasing. A higher amount of assets enlarges the constraint set of the parent with at least one allocation that strictly improves his welfare: the one in which he consumes all the extra wealth in period $t$.

The monotonicity of $b_{t+2}(\cdot)$ is shown as follows. The definition of the offspring's saving policy at $b_{t+1}$ implies that, for $\varepsilon>0$, we have

$$
\begin{aligned}
& u\left(R_{t+1} b_{t+1}+w_{t+1}-b_{t+2}\left(b_{t+1}\right)\right)-u\left(R_{t+1} b_{t+1}+w_{t+1}-b_{t+2}\left(b_{t+1}+\varepsilon\right)\right) \\
\geq & \beta \delta\left[V\left(R_{t+2} b_{t+2}\left(b_{t+1}+\varepsilon\right)+w_{t+2}, Q_{t+2}\right)-V\left(R_{t+2} b_{t+2}\left(b_{t+1}\right)+w_{t+2}, Q_{t+2}\right)\right] .
\end{aligned}
$$

Using the definition of the policy for the offspring at $b_{t+1}+\varepsilon$, we have

$$
\begin{aligned}
& u\left(R_{t+1}\left(b_{t+1}+\epsilon\right)+w_{t+1}-b_{t+2}\left(b_{t+1}\right)\right)-u\left(R_{t+1}\left(b_{t+1}+\varepsilon\right)+w_{t+1}-b_{t+2}\left(b_{t+1}+\epsilon\right)\right) \\
\leq & \beta \delta\left[R_{t+2} V\left(b_{t+2}\left(b_{t+1}+\varepsilon\right)+w_{t+2}, Q_{t+2}\right)-V\left(R_{t+2} b_{t+2}\left(b_{t+1}\right)+w_{t+2}, Q_{t+2}\right)\right] .
\end{aligned}
$$

Combining (38) and (39), we get

$$
\begin{aligned}
& u\left(R_{t+1} b_{t+1}+w_{t+1}-b_{t+2}\left(b_{t+1}\right)\right)-u\left(R_{t+1} b_{t+1}+w_{t+1}-b_{t+2}\left(b_{t+1}+\varepsilon\right)\right) \\
\geq & u\left(R_{t+1}\left(b_{t+1}+\varepsilon\right)+w_{t+1}-b_{t+2}\left(b_{t+1}\right)\right)-u\left(R_{t+1}\left(b_{t+1}+\varepsilon\right)+w_{t+1}-b_{t+2}\left(b_{t+1}+\varepsilon\right)\right) .
\end{aligned}
$$

Assume for the sake of contradiction that $b_{t+2}\left(b_{t+1}+\varepsilon\right)<b_{t+2}\left(b_{t+1}\right)$. Combined with strict concavity of $u$, this contradicts with $(40)$. Thus, it must be that $b_{t+2}\left(b_{t+1}+\varepsilon\right) \geq b_{t+2}\left(b_{t+1}\right)$.

Lemma 16. Suppose the value function $V\left(\cdot, Q_{t}\right)$ is differentiable. Then,$b_{t+2}(\cdot)$ is strictly monotone in the amount of bequests received.

Proof. Due to Inada assumption on the utility function, the solution to the offspring's problem stated in (2) must be interior. A necessary condition for the optimality of offspring's savings is then

$$
u^{\prime}\left(R_{t+1} b_{t+1}+w_{t+1}-b_{t+2}\right)=\beta \delta R_{t+1} V_{1}\left(R_{t+2} b_{t+2}+w_{t+2}, Q_{t+2}\right) R_{t+2} .
$$


Now suppose the offspring receives a higher level of bequests from the parent, $b_{t+1}+x$, where $x>0$. It would never be optimal for the offspring to use all of the increase in his wealth for current consumption since this does not satisfy his necessary condition for optimality:

$$
u^{\prime}\left(R_{t+1}\left(b_{t+1}+x\right)+w_{t+1}-b_{t+2}\right)<\beta \delta R_{t+1} V_{1}\left(R_{t+2} b_{t+2}+w_{t+2}, Q_{t+2}\right) R_{t+2}
$$

which follows from 41 and the strict concavity of the utility function.

Proof. (Core Proof of Proposition 1) In the proof of this proposition, we use monotonicity of $b_{t+2}(\cdot)$ and strict monotonicity of $V(\cdot)$, which we establish in Lemma 15.

Assume for the sake of finding a contradiction that in equilibrium

$$
-u^{\prime}\left(R_{t} b_{t}+w_{t}-b_{t+1}\right)+\gamma R_{t+1} u^{\prime}\left(R_{t+1} b_{t+1}+w_{t+1}-b_{t+2}\left(b_{t+1}\right)\right)>0 .
$$

We want to show that there is a small positive $\varepsilon>0$ such that

$$
\begin{aligned}
& u\left(R_{t} b_{t}+w_{t}-b_{t+1}-\varepsilon\right)+\gamma\left[u\left(R_{t+1}\left(b_{t+1}+\varepsilon\right)+w_{t+1}-b_{t+2}\left(b_{t+1}+\varepsilon\right)\right)+\delta V\left(R_{t+2} b_{t+2}\left(b_{t+1}+\varepsilon\right)+w_{t+2}, Q_{t+2}\right)\right] \\
& >u\left(R_{t} b_{t}+w_{t}-b_{t+1}\right)+\gamma\left[u\left(R_{t+1} b_{t+1}+w_{t+1}-b_{t+2}\left(b_{t+1}\right)\right)+\delta V\left(R_{t+2} b_{t+2}\left(b_{t+1}\right)+w_{t+2}, Q_{t+2}\right)\right]
\end{aligned}
$$

Since $u$ is a differentiable function, for $\varepsilon$ sufficiently small, under the assumption (42), we have

$$
\begin{aligned}
& u\left(R_{t} b_{t}+w_{t}-b_{t+1}-\varepsilon\right)+\gamma u\left(R_{t+1}\left(b_{t+1}+\varepsilon\right)+w_{t+1}-b_{t+2}\left(b_{t+1}\right)\right) \\
> & u\left(R_{t} b_{t}+w_{t}-b_{t+1}\right)+\gamma u\left(R_{t+1} b_{t+1}+w_{t+1}-b_{t+2}\left(b_{t+1}\right)\right) .
\end{aligned}
$$

Then, we have

$$
\begin{aligned}
& u\left(R_{t} b_{t}+w_{t}-b_{t+1}-\varepsilon\right)+\gamma\left[u\left(R_{t+1}\left(b_{t+1}+\varepsilon\right)+w_{t+1}-b_{t+2}\left(b_{t+1}+\varepsilon\right)\right)+\delta V\left(R_{t+2} b_{t+2}\left(b_{t+1}+\varepsilon\right)+w_{t+2}, Q_{t+2}\right)\right] \\
& \geq u\left(R_{t} b_{t}+w_{t}-b_{t+1}-\varepsilon\right)+\gamma\left[\begin{array}{r}
u\left(R_{t+1}\left(b_{t+1}+\varepsilon\right)+w_{t+1}-b_{t+2}\left(b_{t+1}\right)\right)+\beta \delta V\left(R_{t+2} b_{t+2}\left(b_{t+1}\right)+w_{t+2}, Q_{t+2}\right) \\
+(1-\beta) \delta V\left(R_{t+2} b_{t+2}\left(b_{t+1}+\varepsilon\right)+w_{t+2}, Q_{t+2}\right)
\end{array}\right] \\
& >u\left(R_{t} b_{t}+w_{t}-b_{t+1}\right)+\gamma\left[\begin{array}{c}
u\left(R_{t+1} b_{t+1}+w_{t+1}-b_{t+2}\left(b_{t+1}\right)\right)+\beta \delta V\left(R_{t+2} b_{t+2}\left(b_{t+1}\right)+w_{t+2}, Q_{t+2}\right) \\
+(1-\beta) \delta V\left(R_{t+2} b_{t+2}\left(b_{t+1}+\varepsilon\right)+w_{t+2}, Q_{t+2}\right)
\end{array}\right] \\
& \geq u\left(R_{t} b_{t}+w_{t}-b_{t+1}\right)+\gamma\left[\begin{array}{c}
u\left(R_{t+1} b_{t+1}+w_{t+1}-b_{t+2}\left(b_{t+1}\right)\right)+\beta \delta V\left(R_{t+2} b_{t+2}\left(b_{t+1}\right)+w_{t+2}, Q_{t+2}\right) \\
+(1-\beta) \delta V\left(R_{t+2} b_{t+2}\left(b_{t+1}\right)+w_{t+2}, Q_{t+2}\right)
\end{array}\right]
\end{aligned}
$$

where the first inequality follows from the definition of the policy $b_{t+2}(\cdot)$ and the monotonicity of both $b_{t+2}(\cdot)$ and $V\left(\cdot, Q_{t}\right)$, the second inequality follows from 42 and the differentiability of the utility function $u$ as discussed above, and the last one from the monotonicity of both $b_{t+2}(\cdot)$ and 
$V\left(\cdot, Q_{t}\right)$ and the fact that $\beta<1$. It is now easy to see that the last row will have a strict inequality whenever the policy $b_{t+2}(\cdot)$ is strictly monotone since $V$ is actually strictly increasing. In this case, following the same line of proof we can show a contradiction to the weak inequality version of (42).

The case of $\beta>1$ can be shown in an identical way. The case of $\beta=1$ is trivial.

\section{A.2 Proof of Proposition 2}

We start the proof with a preliminary lemma.

Lemma 17. Let $\left\{c_{t}, k_{t}\right\}_{t=0}^{\infty}$ and (interior) equilibrium allocation. Let $c_{s+1}$ and $c_{s+2}$ be the consumption of an agent in his two years of life (with $c_{s+1}$ consumption when young, and $c_{s+2}$ when parent), and $b_{s+2}$ the agent's level of saving from period $s+1$ to $s+2$, which equals in equilibrium the level of capital generated $k_{s+2}$. Then, the following condition has to hold in equilibrium:

$$
-u^{\prime}\left(c_{s+1}\right)+\beta \delta f^{\prime}\left(k_{s+2}\right) u^{\prime}\left(c_{s+2}\right)=0
$$

Proof. Recall that our equilibrium allocations are interior. The key point here is that the same individual is choosing both $b_{s+2}$ and $c_{s+2}$. In particular, the agent can always consider the usual Euler perturbation. The optimal choice of $b_{s+2}$ must be such that there is no feasible deviation around $b_{t+2}$ (keeping both $b_{s+1}$ and $b_{s+3}$ unchanged) that improves over $b_{t+2}$. The agent optimal decision must be such that the problem

$$
\max _{\hat{x} \in N} u\left(R_{s+1} b_{s+1}+w_{s+1}-b_{s+2}-\hat{x}\right)+\delta \beta u\left(R_{s+2}\left(b_{s+2}+\hat{x}\right)+w_{s+2}-b_{s+3}\right)
$$

where $N$ is an open interval around zero, has solution $\hat{x}^{*}=0$. Since $u(\cdot)$ is differentiable, and recalling that $R_{s+2}=f^{\prime}\left(k_{s+2}\right)$ and $b_{s+2}=k_{s+2}$, the necessary condition for $\hat{x}^{*}=0$ to be optimal is the first order condition displayed in the statement of the lemma.

We will prove the statement for the case $\beta<1$. The proof of the case of $\beta>1$ is symmetric. For notational simplicity, we will make the perturbation for consumption in periods 0,1 , and 2 . Define a perturbation by $\hat{c}_{0}=c_{0}-\varepsilon, \hat{c}_{1}=c_{1}+f\left(k_{1}+\varepsilon\right)-f\left(k_{1}\right)-\eta$, and $\hat{c}_{2}=c_{2}+f\left(k_{2}+\eta\right)-f\left(k_{2}\right)$.

Proof. (Core Proof of Proposition 2) We will show that there exist $\varepsilon$ and $\eta$ such that this perturbation makes both the initial parent and the agent who is born in period 1 strictly better off. The welfare of future generations will not be altered since the perturbation only involves periods 0,1 , and 2 .First, wel show that the offspring's welfare increases. We aim at showing that $u\left(c_{1}+f\left(k_{1}+\varepsilon\right)-f\left(k_{1}\right)-\right.$ $\eta)+\delta \beta u\left(c_{2}+f\left(k_{2}+\eta\right)-f\left(k_{2}\right)\right)-\left[u\left(c_{1}\right)+\delta \beta u\left(c_{2}\right)\right]>0$. Letting $\varepsilon=\xi \eta$ with $\xi>0$ to be chosen, 
the same condition is equivalent to itself divided by the positive number $\eta$. So, for $\eta>0$ we have

$$
\begin{aligned}
& u\left(c_{1}+f\left(k_{1}+\xi \eta\right)-f\left(k_{1}\right)-\eta\right)+\delta \beta u\left(c_{2}+f\left(k_{2}+\eta\right)-f\left(k_{2}\right)\right)-\left[u\left(c_{1}\right)+\delta \beta u\left(c_{2}\right)\right]>0 \\
& \frac{u\left(c_{1}+f\left(k_{1}+\xi \eta\right)-f\left(k_{1}\right)-\eta\right)+\delta \beta u\left(c_{2}+f\left(k_{2}+\eta\right)-f\left(k_{2}\right)\right)-\left[u\left(c_{1}\right)+\delta \beta u\left(c_{2}\right)\right]}{\eta}>0 .
\end{aligned}
$$

Since $u(\cdot)$ and $f(\cdot)$ are differentiable, we have:

$$
\begin{aligned}
& u\left(c_{1}+f\left(k_{1}+\xi \eta\right)-f\left(k_{1}\right)-\eta\right)+\delta \beta u\left(c_{2}+f\left(k_{2}+\eta\right)-f\left(k_{2}\right)\right)-\left[u\left(c_{1}\right)+\delta \beta u\left(c_{2}\right)\right] \\
= & {\left[\left(\xi f^{\prime}\left(k_{1}\right)-1\right) u^{\prime}\left(c_{1}\right)+\delta \beta f^{\prime}\left(k_{2}\right) u^{\prime}\left(c_{2}\right)\right] \eta+\mathcal{O}(\eta), }
\end{aligned}
$$

where, by definition of the 'little oh' (as the right derivative exists),

$$
\lim _{\eta \rightarrow 0^{+}, \eta>0} \frac{\mathcal{O}(\eta)}{\eta}=0
$$

Hence for $\eta^{*}>0$ small enough we have

$$
\frac{\left[\left(\xi f^{\prime}\left(k_{1}\right)-1\right) u^{\prime}\left(c_{1}\right)+\delta \beta f^{\prime}\left(k_{2}\right) u^{\prime}\left(c_{2}\right)\right] \eta^{*}}{\eta^{*}}+\frac{\mathcal{O}\left(\eta^{*}\right)}{\eta^{*}}=\xi f^{\prime}\left(k_{1}\right) u^{\prime}\left(c_{1}\right)+\frac{\mathcal{O}\left(\eta^{*}\right)}{\eta^{*}}>0,
$$

where we use Lemma $17^{36}$

Next, we compute the change in welfare for the parent. Recall, $\varepsilon=\xi \eta$. Set

$$
\xi:=\frac{(1-\beta) \gamma \delta f^{\prime}\left(k_{2}\right) u^{\prime}\left(c_{2}\right)}{1+u^{\prime}\left(c_{0}\right)-\gamma \delta \beta f^{\prime}\left(k_{1}\right) f^{\prime}\left(k_{2}\right) u^{\prime}\left(c_{2}\right)}>0
$$

Then, since $u(\cdot)$ and $f(\cdot)$ are differentiable, following the same argument as above, we can find a small enough $\eta$ such that:

$\frac{u\left(c_{0}-\xi \eta\right)+\gamma u\left(c_{1}+f\left(k_{1}+\xi \eta\right)-f\left(k_{1}\right)-\eta\right)+\gamma \delta u\left(c_{2}+f\left(k_{2}+\eta\right)-f\left(k_{2}\right)\right)-\left[u\left(c_{0}\right)+\gamma u\left(c_{1}\right)+\gamma \delta u\left(c_{2}\right)\right]}{\eta}>0$

if and only if

$$
-\xi u^{\prime}\left(c_{0}\right)+\gamma\left(\xi f^{\prime}\left(k_{1}\right)-1\right) u^{\prime}\left(c_{1}\right)+\gamma \delta f^{\prime}\left(k_{2}\right) u^{\prime}\left(c_{2}\right)>0 .
$$

\footnotetext{
${ }^{36}$ To see in more detail why we can guarantee the existence of such $\eta^{*}$ recall that the definition of $\mathcal{O}(\cdot)$ implies that for all $\zeta>0$ we can find a $\psi>0$ such that for all $\eta<\psi$ we have $\left|\frac{\mathcal{O}\left(\eta^{*}\right)}{\eta^{*}}\right|<\zeta$. Thus, since $\xi f^{\prime}\left(k_{1}\right) u^{\prime}\left(c_{1}\right)>0$, we can find $0<\zeta^{*}<\xi f^{\prime}\left(k_{1}\right) u^{\prime}\left(c_{1}\right)$ such that for all $0<\eta^{*}<\psi^{*}$ the requirement is satisfied.
} 
But the latter inequality must be true as we have:

$$
\begin{aligned}
& -\xi u^{\prime}\left(c_{0}\right)+\gamma\left(\xi f^{\prime}\left(k_{1}\right)-1\right) u^{\prime}\left(c_{1}\right)+\gamma \delta f^{\prime}\left(k_{2}\right) u^{\prime}\left(c_{2}\right) \\
& =-\xi\left[u^{\prime}\left(c_{0}\right)-\gamma \beta \delta f^{\prime}\left(k_{1}\right) f^{\prime}\left(k_{2}\right) u^{\prime}\left(c_{2}\right)\right]+(1-\beta) \gamma \delta f^{\prime}\left(k_{2}\right) u^{\prime}\left(c_{2}\right)>0 .
\end{aligned}
$$

The equality between the first and second rows uses Lemma 17 to replace $u^{\prime}\left(c_{1}\right)$ for $\beta \delta f^{\prime}\left(k_{2}\right) u^{\prime}\left(c_{2}\right)$ and rearranging terms whereas the last inequality comes from our definition of $\xi$ which directly implies $\xi\left[u^{\prime}\left(c_{0}\right)-\gamma \beta \delta f^{\prime}\left(k_{1}\right) f^{\prime}\left(k_{2}\right) u^{\prime}\left(c_{2}\right)\right]<(1-\beta) \gamma \delta f^{\prime}\left(k_{2}\right) u^{\prime}\left(c_{2}\right)$.

For the case $\beta>1$, define a perturbation by $\hat{c}_{0}=c_{0}-\varepsilon, \hat{c}_{1}=c_{1}+f\left(k_{1}+\varepsilon\right)-f\left(k_{1}\right)+\eta$, and $\hat{c}_{2}=c_{2}+f\left(k_{2}-\eta\right)-f\left(k_{2}\right)$.

Following the same steps as above, for small $\eta>0$, the change in offspring welfare again

reduces to (disregarding the part $\frac{\mathcal{O}(\eta)}{\eta}$ since it goes to 0 as $\eta$ goes to 0$) u^{\prime}\left(c_{1}\right) \xi f^{\prime}\left(k_{1}\right)$, which is strictly positive. The change in parental welfare reduces to:

$$
-\xi\left[u^{\prime}\left(c_{0}\right)-\gamma \beta \delta f^{\prime}\left(k_{1}\right) f^{\prime}\left(k_{2}\right) u^{\prime}\left(c_{2}\right)\right]+(\beta-1) \gamma \delta f^{\prime}\left(k_{2}\right) u^{\prime}\left(c_{2}\right)>0,
$$

which is strictly positive since both of the terms in this expression are positive and at least one of them is strictly positive.

\section{A.3 Proof of Proposition 7}

Proof. Given any joint sequence of prices and taxes $\Psi$, let

$$
\Gamma_{s}(b)=R_{s}\left(1-\tau_{s}\right) b+w_{s}+T_{s}+G_{s}
$$

be the net present value of wealth as of the beginning of period $s$ of an agent who saved $b$ units in the previous period (of course, we only consider prices and taxes such that this sum converges), where $G_{s}$ denotes the net present value of wages and lump-sum taxes from period $s+1$ onwards

$$
G_{s}=\sum_{m=1}^{\infty} \frac{w_{s+m}+T_{s+m}}{\Pi_{n=1}^{m} R_{s+n}\left(1-\tau_{s+n}\right)}=\frac{w_{s+1}+T_{s+1}+G_{s+1}}{R_{s+1}\left(1-\tau_{s+1}\right)}
$$

We are going to construct an equilibrium in which agents' policies are linear in the current net present value of wealth. We do so in three steps.

Step 1.

We first guess that the value function of the parent has the form

$$
V\left(R_{s}\left(1-\tau_{s}\right) b+w_{s}+T_{s}, \Psi_{s}\right)=\hat{V}\left(\Gamma_{s}(b), \Psi_{s}\right)
$$


where $\hat{V}$ is homogeneous of degree $1-\rho \leq 1$ in period $s$ net present value of wealth, that is

$$
\hat{V}\left(\lambda \Gamma_{s}(b), \Psi_{s}\right)=\lambda^{1-\rho} \hat{V}\left(\Gamma_{\mathcal{S}}(b), \Psi_{s}\right), \quad \forall \lambda>0
$$

Step 2.

We now show that, given this guess about the value function, the consumption policy of period $s$ is linear in $\Gamma_{s}(b)$ for each period $s$. In Step 3, we will verify that this policy indeed generates a value function that has homogeneity of degree $1-\rho$ in $\Gamma_{s}(b)$.

We proceed by backward induction. Consider the problem of an offspring in period $s+1$.

Claim 1.

$$
\begin{array}{r}
\hat{c}_{s+1} \text { solves } \max u\left(c_{s+1}\right)+\beta \delta \hat{V}\left(\Gamma_{s+2}\left(b_{s+2}\right), \Psi_{s+2}\right) \text { s.t. } c_{s+1}+b_{s+2}=\Gamma_{s+1}\left(b_{s+1}\right)-G_{s+1} \\
\text { if and only if } \\
\lambda \hat{c}_{s+1} \text { solves } \max u\left(c_{s+1}\right)+\beta \delta \hat{V}\left(\Gamma_{s+2}\left(b_{s+2}\right), \Psi_{s+2}\right) \text { s.t. } c_{s+1}+b_{s+2}=\lambda \Gamma_{s+1}\left(b_{s+1}\right)-G_{s+1} .
\end{array}
$$

First we show that budget constraint is homogenous of degree 1 in consumption and net present value of wealth. To do so, let $\Gamma_{s+1}\left(\hat{b}_{s+1}\right)$, be the period $s+1$ net present value of wealth when $\Gamma_{s}\left(b_{s}\right)$ is period $s$ net present value of wealth and period $s$ consumption choice is $\hat{c}_{s}$. Now we show that when period $s$ wealth is $\lambda \Gamma_{s}\left(b_{s}\right)$ and the agent consumes $\lambda \hat{c}_{s}$ in period $s$, then period $s+1$ net present value of wealth will be $\lambda \Gamma_{s+1}\left(b_{s+1}\right)$. First, observe that period $s$ saving in the latter case is given by

$$
\left[\lambda \Gamma_{s}\left(b_{s}\right)-G_{s}-\lambda \hat{c}_{s}\right]
$$

Plugging this value in the definition of net present value of wealth for period $s+1$, we get:

$$
\begin{aligned}
& R_{s+1}\left(1-\tau_{s+1}\right)\left[\lambda \Gamma_{s}\left(b_{s}\right)-G_{s}-\lambda \hat{c}_{s}\right]+w_{s+1}+T_{s+1}+G_{s+1} \\
= & \lambda \Gamma_{s}\left(b_{s}\right) R_{s+1}\left(1-\tau_{s+1}\right)-\lambda \hat{c}_{s} R_{s+1}\left(1-\tau_{s+1}\right)-G_{s} R_{s+1}\left(1-\tau_{s+1}\right)+T_{s+1}+G_{s+1} \\
= & \lambda\left[\Gamma_{s}\left(b_{s-1}\right) R_{s}\left(1-\tau_{s}\right)-\hat{c}_{s} R_{s}\left(1-\tau_{s}\right)\right] \\
= & \lambda \Gamma_{s+1}\left(\hat{b}_{s+1}\right) .
\end{aligned}
$$

Suppose $\hat{c}_{s+1}$ solves

$$
\max u\left(c_{s+1}\right)+\beta \delta \hat{V}\left(\Gamma_{s+2}\left(b_{s+2}\right), \Psi_{s+2}\right)
$$

s.t. $c_{s+1}+b_{s+2}=\Gamma_{s+1}\left(b_{s+1}\right)-G_{s+1}$, and for the sake of contradiction suppose $\lambda \hat{c}_{s+1}$ does not solve

$$
\sup u\left(c_{s+1}\right)+\beta \delta \hat{V}\left(\Gamma_{s+2}\left(b_{s+2}\right), \Psi_{s+2}\right)
$$

s.t. $c_{s+1}+b_{s+2}=\lambda \Gamma_{s+1}\left(b_{s+1}\right)-G_{s+1}$. Let $v^{*}$ be the solution of the previous supremum problem and 
define

$$
\kappa:=v^{*}-\left[u\left(\lambda \hat{c}_{s+1}\right)+\beta \delta \hat{V}\left(\lambda \Gamma_{s+2}\left(\hat{b}_{s+2}\right), \Psi_{s+2}\right)\right]>0 .
$$

Under our assumptions, for each $\varepsilon>0$ there is a feasible $\bar{c}_{s+1}^{\varepsilon}$ such that

$$
u\left(\bar{c}_{s+1}^{\varepsilon}\right)+\beta \delta \hat{V}\left(\Gamma_{s+2}\left(\bar{b}_{s+2}^{\varepsilon}\right), \Psi_{s+2}\right)>u\left(\lambda \hat{c}_{s+1}\right)+\beta \delta \hat{V}\left(\lambda \Gamma_{s+2}\left(\hat{b}_{s+2}\right), \Psi_{s+2}\right)+\kappa-\varepsilon,
$$

where $\bar{b}_{s+2}^{\varepsilon}$ is adjusted so as to maintain feasibility. By homogeneity of the utility and value functions, for all $\lambda>0$ the previous statement is equivalent to

$$
u\left(\frac{\bar{c}_{s+1}^{\varepsilon}}{\lambda}\right)+\beta \delta \hat{V}\left(\frac{\Gamma_{s+2}\left(\bar{b}_{s+2}^{\varepsilon}\right)}{\lambda}, \Psi_{s+2}\right)>u\left(\hat{c}_{s+1}\right)+\beta \delta \hat{V}\left(\Gamma_{s+2}\left(\hat{b}_{s+2}\right), \Psi_{s+2}\right)+\frac{\kappa-\varepsilon}{\lambda} .
$$

We also know that if $\bar{c}_{s+1}^{\varepsilon}$ and $\Gamma_{s+2}\left(\bar{b}_{s+2}^{\varepsilon}\right)$ are feasible in the problem of the agent facing wealth $\lambda \Gamma_{s+1}\left(b_{s+1}\right)$, so are $\frac{\bar{c}_{s+1}^{\varepsilon}}{\lambda}$ and $\frac{\Gamma_{s+2}\left(\bar{b}_{s+2}^{\varepsilon}\right)}{\lambda}$ in the problem of the agent facing $\Gamma_{s+1}\left(b_{s+1}\right)$. Setting $\varepsilon^{*}=\frac{\kappa}{2}>$ 0 , we obtain a contradiction since $\frac{\bar{c}_{s+1}^{\varepsilon^{*}}}{\lambda}$ and $\frac{\Gamma_{s+2}\left(\bar{b}_{s+2}^{*^{*}}\right)}{\lambda}$ are feasible and give strictly higher utility to the agent's problem in year $s$. The converse of the claim is shown symmetrically.

Now, we prove the second step in the backward induction.

Claim 2.

$$
\left(\hat{c}_{s}, \hat{c}_{s+1}\right) \text { solves } \max u\left(c_{s}\right)+\gamma\left[u\left(c_{s+1}\right)+\delta \hat{V}\left(\Gamma_{s+2}\left(b_{s+2}\right), \Psi_{s+2}\right)\right]
$$

s.t. (1) $c_{s}+b_{s+1}=\Gamma_{s}\left(b_{s}\right)-G_{s}$ and (2) $c_{s+1}$ solves agent's problem in year $s+1$

if and only if

$$
\left(\lambda \hat{c}_{s}, \lambda \hat{c}_{s+1}\right) \text { solves } \max u\left(c_{s}\right)+\gamma\left[u\left(c_{s+1}\right)+\delta \hat{V}\left(\Gamma_{s+2}\left(b_{s+2}\right), \Psi_{s+2}\right)\right]
$$

s.t. (3) $c_{s}+b_{s+1}=\lambda \Gamma_{s}\left(b_{s}\right)-G_{s}$ and (4) $c_{s+1}$ solves agent's problem in year $s+1$.

Suppose for the sake of contradiction that $\left(\hat{c}_{s}, \hat{c}_{s+1}\right)$ solves the corresponding problem but $\left(\lambda \hat{c}_{s}, \lambda \hat{c}_{s+1}\right)$ does not. Since the proof follows the same principle as that in the proof of Claim 1, to save notation, we now propose the proof assuming existence of a solution for both problems. This assumption is not needed as we have shown above. Then, there exists a $\left(\bar{c}_{s}, \bar{c}_{s+1}\right)$ such that

$$
u\left(\bar{c}_{s}\right)+\gamma\left[u\left(\bar{c}_{s+1}\right)+\delta \hat{V}\left(\Gamma_{s+2}\left(\bar{b}_{s+2}\right), \Psi_{s+2}\right)\right]>u\left(\lambda \hat{c}_{s}\right)+\gamma\left[u\left(\lambda \hat{c}_{s+1}\right)+\delta \hat{V}\left(\lambda \Gamma_{s+2}\left(\hat{b}_{s+2}\right), \Psi_{s+2}\right)\right],
$$

and (3) and (4) are satisfied. By homogeneity of utility and value functions, we have

$$
u\left(\frac{\bar{c}_{s}}{\lambda}\right)+\gamma\left[u\left(\frac{\bar{c}_{s+1}}{\lambda}\right)+\delta \hat{V}\left(\frac{\Gamma_{s+2}\left(\bar{b}_{s+2}\right)}{\lambda}, \Psi_{s+2}\right)\right]>u\left(\hat{c}_{s}\right)+\gamma\left[u\left(\hat{c}_{s+1}\right)+\delta \hat{V}\left(\Gamma_{s+2}\left(\hat{b}_{s+2}\right), \Psi_{s+2}\right)\right] .
$$


Furthermore, as we have shown in the first step of the induction, if $\bar{c}_{s+1}$ solves the problem in year $s+1$ under $\Gamma_{s+1}\left(\bar{b}_{s+1}\right)$, then $\frac{\bar{c}_{s+1}}{\lambda}$ solves the same problem under $\frac{\Gamma_{s+1}\left(\bar{b}_{s+1}\right)}{\lambda}$. This means that $\left(\frac{\bar{c}_{s}}{\lambda}, \frac{\bar{c}_{s+1}}{\lambda}\right)$ is in the constraint set of the agent's problem in year $s$, which combined with the fact that it gives strictly higher welfare than the equilibrium allocation implies a contradiction.

Step 3.

Now, we verify that, under consumption policies that are linear in the current wealth, the value function is in fact homogeneous of degree $1-\rho$ in $\Gamma$, as assumed:

$$
\begin{aligned}
V\left(\lambda \Gamma_{s}(b), \Psi_{s}\right) & =u\left(\lambda \hat{c}_{s}\right)+\gamma\left[u\left(\lambda \hat{c}_{s+1}\right)+\delta V\left(\lambda \Gamma_{s+2}\left(\hat{b}_{s+2}\right), \Psi_{s+2}\right)\right] \\
& =\frac{\left(\lambda \hat{c}_{s}\right)^{1-\rho}}{1-\rho} \gamma\left[\frac{\left(\lambda \hat{c}_{s+1}\right)^{1-\rho}}{1-\rho}+\lambda^{1-\rho} \delta V\left(\Gamma_{s+2}\left(\hat{b}_{s+2}\right), \Psi_{s+2}\right)\right] \\
& =\lambda^{1-\rho}\left\{u\left(\hat{c}_{s}\right)+\gamma\left[u\left(\hat{c}_{s+1}\right)+\delta V\left(\Gamma_{s+2}\left(\hat{b}_{s+2}\right), \Psi_{s+2}\right)\right]\right\} \\
& =\lambda^{1-\rho} V\left(\Gamma_{s}(b), \Psi_{s}\right) .
\end{aligned}
$$

To complete the proof, observe that we have shown that consumption defined as a function of net present value of wealth, prices, and taxes, denote it by $c_{S}\left(\Gamma_{S}(b), \Psi_{s}\right)$, satisfies the following homogeneity of degree one in wealth:

$$
c_{S}\left(\lambda \Gamma_{s}(b), \Psi_{s}\right)=\lambda c_{S}\left(\Gamma_{s}(b), \Psi_{s}\right)
$$

In particular this implies

$$
c_{S}\left(\Gamma_{S}(b), \Psi_{S}\right)=\Gamma_{S}(b) c_{S}\left(1, \Psi_{S}\right)
$$

which means consumption is a linear function of wealth with a constant multiplier of $c_{S}\left(1, \Psi_{s}\right)$.

Using the homogeneity of the value function, we can show that the value function has the following simple form as a function of wealth:

$$
V\left(\Gamma_{s}(b), \Psi_{s}\right)=\Gamma_{S}(b)^{1-\rho} V\left(1, \Psi_{s}\right)
$$

This ends the proof. Note in particular, that since we are driving conditions for an equilibrium, no verification stage is needed.

\section{A.4 Proof of Proposition 8}

Proof. The proof proceeds in two steps. In the first step, for logarithmic utility, we compute closed form solution for equilibrium linear consumption policy as a function of net present value of wealth and tax-price sequence. In the second step, we use the consumption policy computed in step one to compute $M_{t+2}^{*}$ and plug that in the tax formula in Proposition 6 
Step 1. We use guess and verify method to compute value and policy functions. First, remember from the proof of Proposition 7 that, given any joint sequence of taxes and prices $\Psi$, we can write the parent's value function as a function of his current net present value of wealth $\hat{V}\left(\Gamma_{t}\left(b_{t}\right), \Psi_{t}\right)$, where $\Gamma_{t}\left(b_{t}\right)$ represents the current net present value of wealth of a parent who saved $b_{t}$ units during his young adulthood in period $t-1$. (Observe that in fact $\Gamma_{t}\left(b_{t}\right)$ also depends on the tax-price sequence $\Psi_{t}$, however, we omit to make this dependence explicit in order to ease notation). Now, we guess that the value function has the following form:

$$
\hat{V}\left(\Gamma_{t}\left(b_{t}\right), \Psi_{t}\right)=D \log \left(\Gamma_{t}\left(b_{t}\right)\right)+B\left(\Psi_{t}\right)
$$

where $D$ is the constant of the parent's value function.

By assumption we are interested in equilibria where policies are linear in net present value of wealth. Therefore, let consumption in period $t$ under wealth $\Gamma_{t}\left(b_{t}\right)$ be given by

$$
c_{t}\left(\Gamma_{t}\left(b_{t}\right), \Psi_{t}\right)=C_{t}\left(\Psi_{t}\right) \Gamma_{t}\left(b_{t}\right)
$$

where $C_{t}\left(\Psi_{t}\right)$ is the fraction of wealth consumed by agent under $\Psi_{t}$. In what follows, we omit the dependence of $C_{t}$ on $\Psi_{t}$ in order to ease notation. Using linearity of the policy functions, we can rewrite the parent's problem as:

$$
\begin{gathered}
\hat{V}\left(\Gamma_{t}\left(b_{t}\right), \Psi_{t}\right)=\max _{C_{t}} u\left(C_{t} \Gamma_{t}\left(b_{t}\right)\right)+\gamma\left[u\left(C_{t+1} \Gamma_{t+1}\left(b_{t+1}\right)\right)+\delta \hat{V}\left(\Gamma_{t+2}\left(b_{t+2}\right), \Psi_{t+2}\right)\right] \\
\quad \text { s.t. } \\
u^{\prime}\left(C_{t+1} \Gamma_{t+1}\left(b_{t+1}\right)\right)=\quad \delta \beta \hat{V}_{1}\left(\Gamma_{t+2}\left(b_{t+2}\right), \Psi_{t+2}\right) R_{t+2}\left(1-\tau_{t+2}\right) .
\end{gathered}
$$

Note that net present value of wealth in two consecutive periods are linked as follows:

$$
\begin{aligned}
\Gamma_{t+1}\left(b_{t+1}\right) & =R_{t+1}\left(1-\tau_{t+1}\right) b_{t+1}+w_{t+1}+T_{t+1}+G_{t+1} \\
& =R_{t+1}\left(1-\tau_{t+1}\right)\left[R_{t}\left(1-\tau_{t}\right) b_{t}+w_{t}+T_{t}-C_{t} \Gamma_{t}\left(b_{t}\right)\right]+w_{t+1}+T_{t+1}+G_{t+1} \\
& =R_{t+1}\left(1-\tau_{t+1}\right)\left[R_{t}\left(1-\tau_{t}\right) b_{t}+w_{t}+T_{t}-C_{t} \Gamma_{t}\left(b_{t}\right)+\frac{w_{t+1}+T_{t+1}+G_{t+1}}{R_{t+1}\left(1-\tau_{t+1}\right)}\right] \\
& =R_{t+1}\left(1-\tau_{t+1}\right)\left[R_{t}\left(1-\tau_{t}\right) b_{t}+T_{t}-C_{t} \Gamma_{t}\left(b_{t}\right)+G_{t}\right] \\
& =R_{t+1}\left(1-\tau_{t+1}\right) \Gamma_{t}\left(b_{t}\right)\left[1-C_{t}\right] .
\end{aligned}
$$

Plugging the value function guess in the constraint of the planning problem, 44 , and using $u(\cdot)=$ log, we get: 


$$
\begin{aligned}
\left(C_{t+1} \Gamma_{t+1}\left(b_{t+1}\right)\right)^{-1} & =\frac{\delta \beta R_{t+2}\left(1-\tau_{t+2}\right) D}{\Gamma_{t+2}\left(b_{t+2}\right)} \\
& =\frac{\delta \beta R_{t+2}\left(1-\tau_{t+2}\right) D}{R_{t+2}\left(1-\tau_{t+2}\right)\left(1-C_{t+1}\right) \Gamma_{t+1}\left(b_{t+1}\right)}
\end{aligned}
$$

where the second equality follows from the relationship between consecutive wealth levels that we just established. This implies

$$
\left(C_{t+1}\right)^{-1}=\frac{\delta \beta D}{\left(1-C_{t+1}\right)}
$$

or

$$
C_{t+1}(D)=\frac{1}{1+\delta \beta D}
$$

Taking first-order condition with respect to $C_{t}$ in the parent's problem and using again 45 , we get:

$$
C_{t}(D)=\frac{1}{1+\gamma(1+\delta D)}
$$

Now verify the value function to compute $D$ :

$D \log \left(\Gamma_{t}\left(b_{t}\right)\right)+B\left(\Psi_{t}\right)=\log \left(C_{t}(D) \Gamma_{t}\left(b_{t}\right)\right)+\gamma\left[\log \left(C_{t+1}(D) \Gamma_{t+1}\left(b_{t+1}\right)\right)+\delta\left\{D \log \left(\Gamma_{t+2}\left(b_{t+2}\right)\right)+B\left(\Psi_{t+2}\right)\right\}\right]$, which, using 45 and comparing the coefficients of $\log \left(\Gamma_{t}\left(b_{t}\right)\right)$ on both sides of the above equation, implies

$$
D=\frac{1+\gamma}{1-\gamma \delta}
$$

Step 2. Remember that $b_{t+2}\left(b_{t+1}, \Psi_{t+1}\right)=R_{t+1}\left(1-\tau_{t+1}\right) b_{t+1}+w_{t+1}+T_{t+1}-C_{t+1} \Gamma_{t+1}\left(b_{t+1}\right)$. Thus, we get

$$
\begin{aligned}
M_{t+2}^{*} \equiv \frac{d b_{t+2}\left(b_{t+1}, \Psi_{t+1}\right)}{d b_{t+1}} & =R_{t+1}\left(1-\tau_{t+1}\right)-C_{t+1} R_{t+1}\left(1-\tau_{t+1}\right) \\
& =R_{t+1}\left(1-\tau_{t+1}\right) \frac{\delta \beta D}{1+\delta \beta D}
\end{aligned}
$$

Plugging this $M_{t+2}^{*}$ value in the tax formula in Proposition 6 and doing some simple manipulation, we get the result. 


\section{A.5 Proof of Proposition 9}

Proof. Step 1. We first compute the Ramsey allocation. The euler equations that characterize Ramsey equilibrium are: for $t=0,2,4, \ldots$

$$
\begin{aligned}
u^{\prime}\left(c_{t}^{*}\right) & =\gamma R_{t+1} u^{\prime}\left(c_{t+1}^{*}\right), \\
u^{\prime}\left(c_{t+1}^{*}\right) & =\delta R_{t+2} u^{\prime}\left(c_{t+2}^{*}\right) .
\end{aligned}
$$

Since utility is logarithmic, this implies that for $t=0,2,4, \ldots$

$$
\begin{aligned}
c_{t+1}^{*} & =c_{t}^{*} x_{t+1}, \\
c_{t+2}^{*} & =c_{t+1}^{*} y_{t+2},
\end{aligned}
$$

where

$$
\begin{aligned}
& x_{t+1}=\gamma R_{t+1} \\
& y_{t+2}=\delta R_{t+2}
\end{aligned}
$$

Equivalently, we can write

$$
\begin{aligned}
c_{1}^{*} & =c_{0}^{*} x_{1}, \\
c_{2}^{*} & =c_{0}^{*} x_{1} y_{2}, \\
c_{3}^{*} & =c_{0}^{*} x_{1} y_{2} x_{3}, \\
c_{4}^{*} & =c_{0}^{*} x_{1} y_{2} x_{3} y_{4},
\end{aligned}
$$

Using this in budget, we get

$$
c_{0}^{*}\left(1+\frac{x_{1}}{R_{1}}+\frac{x_{1} y_{2}}{R_{1} R_{2}}+\frac{x_{1} y_{2} x_{3}}{R_{1} R_{2} R_{3}}+\frac{x_{1} y_{2} x_{3} y_{4}}{R_{1} R_{2} R_{3} R_{4}}+\ldots\right)=R_{0} b_{0}+w_{0}+\frac{w_{1}}{R_{1}}+\frac{w_{2}}{R_{1} R_{2}}+\ldots \equiv \Gamma,
$$

which after plugging in values of $x_{t+1}$ and $y_{t+2}$ gives:

$$
c_{0}^{*}\left(1+\gamma+\gamma \delta+\gamma^{2} \delta+\gamma^{2} \delta^{2}+\ldots\right)=\Gamma
$$

implying

$$
c_{0}^{*}=\Gamma \frac{1-\gamma \delta}{1+\gamma} .
$$

Step 2. Next, we compute the laissez-faire equilibrium allocation, which we denote below by 
hat. The euler equations that characterize equilibrium are: for $t=0,2,4, \ldots$

$$
\begin{aligned}
u^{\prime}\left(\hat{c}_{t}\right) & =\frac{\gamma R}{1-\delta+\beta \delta} u^{\prime}\left(\hat{c}_{t+1}\right), \\
u^{\prime}\left(\hat{c}_{t+1}\right) & =\beta \delta R u^{\prime}\left(\hat{c}_{t+2}\right) .
\end{aligned}
$$

Since utility is logarithmic, this implies that for $t=0,2,4, \ldots$

$$
\begin{aligned}
& \hat{c}_{t+1}=\hat{c}_{t} \hat{x}_{t+1}, \\
& \hat{c}_{t+2}=\hat{c}_{t+1} \hat{y}_{t+1},
\end{aligned}
$$

where

$$
\begin{aligned}
\hat{x}_{t+1} & =\frac{\gamma R}{1-\delta+\beta \delta^{\prime}} \\
\hat{y}_{t+2} & =\beta \delta R .
\end{aligned}
$$

Following what we did while computing the Ramsey allocation, we find that

$$
\hat{c}_{0}=\Gamma \frac{1-\delta+\beta \delta-\beta \gamma \delta}{1-\delta+\beta \delta+\gamma}
$$

Step 3. Now we compare the welfare of all generations under the two allocations and find the restrictions on parameters under which Ramsey improves welfare for all.

Notice that the Ramsey allocation strictly increases initial old's welfare over laissez-faire since by definition Ramsey allocation is the unique allocation maximizes initial old's welfare. We need to find when it improves over laissez-faire for the rest of the agents.

Let's first check agent who is born in period 1. Denote his utility under Ramsey allocation by $U_{R A}^{1}$ and that under laissez-faire equilibrium by $U_{L F}^{1}$ :

$$
\begin{aligned}
& U_{R A}^{1}=\log \left(c_{0}^{*} x_{1}\right)+\beta \delta\left[\log \left(c_{0}^{*} x_{1} y_{2}\right)+\gamma \log \left(c_{0}^{*} x_{1} y_{2} x_{3}\right)+\gamma \delta \log \left(c_{0}^{*} x_{1} y_{2} x_{3} y_{4}\right)+\ldots\right] \\
& U_{L F}^{1}=\log \left(\hat{c}_{0} \hat{x}_{1}\right)+\beta \delta\left[\log \left(\hat{c}_{0} \hat{x}_{1} \hat{y}_{2}\right)+\gamma \log \left(\hat{c}_{0} \hat{x}_{1} \hat{y}_{2} \hat{x}_{3}\right)+\gamma \delta \log \left(\hat{c}_{0} \hat{x}_{1} \hat{y}_{2} \hat{x}_{3} \hat{y}_{4}\right)+\ldots\right]
\end{aligned}
$$

Agent 1 is better off under Ramsey allocation if and only if $U_{R A}^{1} \geq U_{L F}^{1}$. But this difference can be computed as follows:

$$
U_{R A}^{1}-U_{L F}^{1}=\left[\log \left(c_{0}^{*}\right)-\log \left(\hat{c}_{0}\right)\right] A+\left[\log (\gamma)-\log \left(\frac{\gamma}{1-\delta+\beta \delta}\right)\right] B+[\log (\delta)-\log (\beta \delta)] C,
$$


where

$$
\begin{array}{r}
A=1+\beta \delta\left[1+\gamma+\gamma \delta+\gamma^{2} \delta+\gamma^{2} \delta^{2}+\ldots\right], \\
B=1+\beta \delta\left[1+2 \gamma+2 \gamma \delta+3 \gamma^{2} \delta+3 \gamma^{2} \delta^{2}+\ldots\right], \\
C=\beta \delta\left[1+\gamma+2 \gamma \delta+2 \gamma^{2} \delta+3 \gamma^{2} \delta^{2}+\ldots\right] .
\end{array}
$$

With some algebra, we can show that

$$
\begin{array}{r}
A=1+\frac{\beta \delta}{1-\gamma \delta}(1+\gamma), \\
B=1+\frac{\beta \delta}{1-\gamma \delta}\left(\frac{1+\gamma}{1-\gamma \delta}+\gamma\right), \\
C=\frac{\beta \delta}{1-\gamma \delta}\left(\frac{1+\gamma}{1-\gamma \delta}\right) .
\end{array}
$$

Plugging in the values of $c_{0}^{*}$ and $\hat{c}_{0}$, condition 46 becomes

$$
U_{R A}^{1}-U_{L F}^{1}=\log \left(\frac{(1-\gamma \delta)(1+\gamma-\delta+\beta \delta)}{(1+\gamma)(1-\gamma \delta \beta-\delta+\beta \delta)}\right) A+\log (1-\delta+\beta \delta) B-\log (\beta) C
$$

Since neither the Ramsey nor the laissez-faire allocations are assumed to be stationary, the fact that agent 1 is better off under Ramsey allocation does not imply that future generations are better off too. Now, we show that condition (47) guarantees that agents born in future generations are better off under Ramsey as well. Let us first look at the agent born in period 3.

$$
\begin{aligned}
U_{R A}^{3} & =\log \left(c_{0}^{*} x_{1} y_{2} x_{3}\right)+\beta \delta\left[\log \left(c_{0}^{*} x_{1} y_{2} x_{3} y_{4}\right)+\gamma \log \left(c_{0}^{*} x_{1} y_{2} x_{3} y_{4} x_{5}\right)+\ldots\right] \\
& =U_{R A}^{1}+\log \left(y_{2} x_{3}\right)+\beta \delta\left[\log \left(x_{3} y_{4}\right)+\gamma \log \left(x_{4} y_{5}\right)+\ldots\right] .
\end{aligned}
$$

Similarly,

$$
U_{L F}^{3}=U_{L F}^{1}+\log \left(\hat{y}_{2} \hat{x}_{3}\right)+\beta \delta\left[\log \left(\hat{x}_{3} \hat{y}_{4}\right)+\gamma \log \left(\hat{x}_{4} \hat{y}_{5}\right)+\ldots\right]
$$

After some algebra, we reach:

$$
\begin{array}{r}
U_{R A}^{3}-U_{L F}^{3}=U_{R A}^{1}-U_{L F}^{1}+\left[\log (\gamma \delta)-\log \left(\frac{\gamma \delta \beta}{1-\delta+\beta \delta}\right)\right] A \\
=U_{R A}^{1}-U_{L F}^{1}-\log \left(\frac{\beta}{1-\delta+\beta \delta}\right) A \\
>U^{1}(x, y)-U^{1}(\hat{x}, \hat{y}),
\end{array}
$$

since $\frac{\beta}{1-\delta+\beta \delta}<1$. Thus, we have shown that condition 47 guarantees that agent 3 is better off 
under Ramsey allocation.

In a similar way, one can show that for any $t$ odd, $U^{t}(x, y)-U^{t}(\hat{x}, \hat{y})>U^{1}(x, y)-U^{1}(\hat{x}, \hat{y})$ ending the proof.

\section{A.6 Proof of Proposition 10}

Proof. When $\gamma=\delta$, then, the condition for Ramsey allocation to be Pareto improving becomes

$$
\log (1-\delta+\beta \delta)\left[1+\frac{\beta \delta}{1-\delta}\left(1+\frac{\delta}{1-\delta^{2}}\right)\right]-\log (\beta) \frac{\beta \delta}{1-\delta} \frac{1}{1-\delta^{2}} \geq 0 .
$$

At no $\beta \in(0,1)$, a limit exists for the above expression as $\delta \rightarrow 1$. But the left and right hand limits exist. Since we are interested in the value as $\delta$ approaches 1 from below, the relevant limit is the left hand one, which is

$$
\lim _{\delta \rightarrow 1^{-}} \log \left(\frac{1}{1-\delta+\beta \delta}\right)\left[1+\frac{\beta \delta}{1-\delta}\left(1+\frac{\delta}{1-\delta^{2}}\right)\right]+\log (\beta) \frac{\beta \delta}{1-\delta} \frac{1}{1-\delta^{2}}=\infty
$$

Thus, we have proved the proposition.

\section{A.7 Proof of Proposition 11}

Proof. We start with deriving the wedge for the offspring. The optimality condition for the planner the perturbation $z_{0}^{\varepsilon}(s)=z_{0}^{*}(s), z_{1}^{\varepsilon}(s)=z_{1}^{*}(s)+\varepsilon$, and $z_{2}^{\varepsilon}(s)=z_{2}^{*}(s)-\frac{\varepsilon}{\delta}$ is

$$
\lambda(1-\beta)-\frac{\mu_{1}}{u^{\prime}\left(c_{1}^{*}(s)\right)}+\frac{\mu_{1}}{\delta R_{2}^{*} u^{\prime}\left(c_{2}^{*}(s)\right)}=0
$$

which can be rearranged as

$$
\frac{\beta-1}{\beta}\left(\frac{\lambda u^{\prime}\left(c_{1}^{*}(s)\right)}{\mu_{1}}-1\right)=\frac{u^{\prime}\left(c_{1}^{*}(s)\right)}{\delta \beta R_{2}^{*} u^{\prime}\left(c_{2}^{*}(s)\right)}-1 .
$$

Notice now a few interesting issues. First, if $\beta=1$ there is no need to generate any wedge on the offspring. This is due to the fact that there is no new information (no skill shocks after period zero) so no need to distort the intertemporal margins to relax the incentive constraint. Second, even when $s$ is private information to the parent, the offspring do not face any direct incentive constraint. This implies that, whenever $\lambda=0$ and $\beta \neq 1$, the wedge becomes $\frac{1-\beta}{\beta}$ which in terms of taxes implies $1-\tau=1+\frac{1-\beta}{\beta}=\frac{1}{\beta}$, the correction needed to get the Ramsey allocation to the offspring and nothing more. Third, when $\lambda>0$ but we have no private information about $s$, full horizontal 
redistribution implies $\mu_{1}=(\gamma+\lambda) u^{\prime}\left(c_{1}^{*}\right)$ and the correction is as in the previous section ${ }^{37}$ Since $c_{1}^{*}(s)$ increases with $s$, the general case where $\lambda>0$ and $\beta \neq 1$ generates a state dependent wedge $-\tau_{2}^{*}(s)$ that increases (resp. decreases) with s whenever $\beta<1$ (resp. $\beta>1$ ). The logic behind this result is similar to that above and it disappears when $\beta=1$. When $\beta<1$ (and $\lambda>0$ ) the planner prefers reducing consumption inequality in $c_{1}$ rather than in $c_{2}$. This is so since distribution through $c_{2}$ improves welfare according to $\delta(\gamma+\lambda \beta)$ while it reduces incentives according to $\delta \gamma$. On the other hand, as we discussed above, for $c_{1}$ the relative weights are $\gamma+\lambda$ and $\gamma$ respectively. For example, when $\beta<1$ the implies tax $1-\tau_{2}^{*}(s)$ increases with s.

Core of the Proof. Consider the problem of a parent endowed with asset level $b_{0}\left(=K_{0}\right)$, skill level $s$, and declaring to be of skill $\sigma$ :

$$
\begin{array}{rl}
V(\sigma \mid s):=\max _{\left\{c_{t}, b_{t}\right\}_{t=0}^{2}} & u\left(c_{0}\right)-v\left(\frac{y_{0}(\sigma)}{w_{0} s}\right)+\gamma\left[u\left(c_{1}\right)+\delta u\left(c_{2}\right)\right] \\
\text { s.t. } & c_{0}+b_{1}=R_{0} b_{0}+y_{0}(\sigma)-T^{b}\left(b_{1}\right)+T_{0}^{y}(\sigma) ; \\
& b_{2} \in \arg \max _{\hat{b}} u\left(\hat{c}_{1}\right)+\delta \beta u\left(\hat{c}_{2}\right) ; \\
\text { s.t. } \hat{c}_{1}+\hat{b}=R_{1}\left(1-\tau_{1}(\sigma)\right) b_{1}+y_{1}+T_{1}^{y}(\sigma) ; \\
\hat{c}_{2}=R_{2}\left(1-\tau_{2}(\sigma)\right) \hat{b}+y_{2}+T_{2}^{y}(\sigma) .
\end{array}
$$

We say that a system of taxes implements the Mirrlees allocation $\left(\left\{c_{t}^{*}(s)\right\}_{t=0,1,2}, y_{0}^{*}(s)\right)_{s \in S^{\prime}}$, if for each $s$ we have $V(s \mid s) \geq V(\sigma \mid s)$ for all $\sigma$ and for each $s$ the solution to $V(s \mid s)$ is $\left(\left\{c_{t}^{*}(s)\right\}_{t=0,1,2}, y_{0}^{*}(s)\right)$.

The core of the implementation exercise follows the same logic as Kocherlakota (2005). We will show that for all $s$ a dynasty whose parent declares $\sigma$ will find optimal to choose the allocation prescribed by the efficient allocation $c_{t}^{*}(\sigma), t=0,1,2$ (and, of course, the parent is forced to generate income $\left.y_{0}^{*}(\sigma)\right)$. One this key fact has been shown, the inequality $V(s \mid s) \geq V(\sigma \mid s)$ is a direct consequence of the incentive compatibility property of the Mirrleesian allocation.

(i)(Ramsey) For all $s$, set $1-\tau_{2}^{*}(s) \equiv \frac{1}{\beta}$. This tax will imply the offspring solves condition 49 with $\lambda=0$, namely

$$
-\tau_{2}^{*}=\frac{1}{\beta}-1=\frac{1-\beta}{\beta}=\frac{u^{\prime}\left(c_{1}^{*}(s)\right)}{\delta \beta R_{2} u^{\prime}\left(c_{2}^{*}(s)\right)}-1 .
$$

Since the offspring problem is strictly concave, the offspring will choose the second best allocation

${ }^{37}$ From 49 under full insurance we have

$$
\frac{u^{\prime}\left(c_{1}^{*}(s)\right)}{\delta \beta R_{2}^{*} u^{\prime}\left(c_{2}^{*}(s)\right)}=1+\frac{\beta-1}{\beta}\left(\frac{\lambda}{\gamma+\lambda}-1\right)=\frac{1}{\beta} \frac{\gamma+\lambda \beta}{\gamma+\lambda},
$$

which is exactly the wedge implied by condition (17) in Section 5.1 
if budget feasible. It hence suffices to choose labor taxes that guarantee

$$
c_{1}^{*}(s)+\frac{c_{2}^{*}(s)}{R_{2}\left(1-\tau_{2}^{*}\right)}=y_{1}+T_{1}^{y}(s)+\frac{y_{2}+T_{2}^{y}(s)}{R_{2}\left(1-\tau_{2}^{*}\right)}+R_{1}\left(1-\tau_{1}^{*}(s)\right) b_{1}^{*}(s) .
$$

In the above, the value $R_{1}\left(1-\tau_{1}^{*}(s)\right) b_{1}^{*}(s)$ as yet to be determined, but it is pretty clear that the presence of state contingent labor income taxes gives enough degrees of freedom to generate feasibility of the Mirrlees allocation for the offspring. Now, recall that from Proposition 7- with CEIS utility - the policy of the kid is linear and increasing in wealth. Let $\frac{\partial b_{2}(\cdot)}{\partial b_{1}}=M^{*}$ the derivative of such a policy 38 As well, recall that when $\lambda=0$ there is no need to distort parental intertemporal margins for redistribution purpose. Stated differently, labor taxes alone suffice to redistribute income across dynasties. Finally, Proposition 6 implies that a positive linear tax implements the optimal allocation. In particular, for all $s$ we have

$$
\tau_{1}^{*}(s) \equiv \frac{M^{*}}{R_{1}}\left[\frac{1}{\beta}-1\right],
$$

which implies again that we can keep the bequest tax independent from $s$ as claimed above, and we can set $T^{b}(\cdot) \equiv 0$. Now note that the actual level of skills do not enter into the inter temporal budget constraint nor into the Euler equations of the individuals. This implies that for all $s$, a parent declaring $\sigma$ (possibly different from $s$ ) will find it optimal to choose the Mirrleese consumption plan $c_{t}^{*}(\sigma), t=0,1,2$. Since the Mirrleese allocation is incentive compatible the parents will actually tell the truth. As we said, there is a continuum of labor taxes generating the net present value of income. One possibility is hence that each parent bequests the same level $b_{1}^{*}=K_{1}$ to his kids. A particularly appealing allocation is the one that uses $T_{0}^{y}(s)$ as a main distributional tool and $T_{1}^{y}(s)$, and $T_{2}^{y}(s)$ to only rebate lump sum the wealth taxes paid. More precisely, if the Mirrlees allocation is implemented by bequest $b_{1}^{*}(s)$ and $b_{2}^{*}(s)$ then for $t=1,2, T_{t}^{y}(s)=\tau_{t}^{*} b_{t}^{*}(s)$. Then $T_{0}^{y}(s)$ is set so that to have the intertemporal budget constraint of the dynasty to hold exactly. In summary, once labor taxes are used to distribute horizontally, bequest taxes and the tax on the offspring are both identical to those studied at the beginning of the paper.

(ii) In this case, the implementation is a little bit more complicated but very similar to that described above for $\lambda=0$. We will keep labor income taxes with the same spirit as above, namely, for $t=1,2$, and all $s, T_{t}^{y}(s)=\tau_{t}^{*}(s) b_{t}^{*}(s)$. Recall that when $\lambda>0$ the wedge on the offspring is state dependent. We will hence set for all $s$

$$
\tau_{2}^{*}(s)=-\frac{\beta-1}{\beta}\left(\frac{\lambda u^{\prime}\left(c_{1}^{*}(s)\right)}{\mu_{1}}-1\right)=1-\frac{u^{\prime}\left(c_{1}^{*}(s)\right)}{\delta \beta R_{2} u^{\prime}\left(c_{2}^{*}(s)\right)} .
$$

Given the tax on offspring savings is state dependent, the offspring policy will be state dependent

\footnotetext{
${ }^{38}$ Note that the kid problem is as above, with the budget linear in $b_{1}$ so the proof of linearity is immediate.
} 
as well, but again linear. This is so since preference safe CEIS and for each given $s$, wealth taxes are linear. Let $M^{*}(s)$ be the derivative of the policy when facing taxes $\tau_{2}(s){ }^{39}$ Now, from equation 10 , we can derive the first order condition for the parent in presence of taxes as:

$$
\frac{u^{\prime}\left(c_{0}(s)\right)\left[1+\frac{\partial T^{b}\left(b_{1}(s)\right)}{\partial b_{1}}\right]}{\gamma R_{1} u^{\prime}\left(c_{1}(s)\right)}=1-\tau_{1}(s)+\frac{M^{*}(s)}{R_{1}}\left[\frac{1}{\beta}-1\right] \text {. }
$$

Now, if we set $\tau_{1}(s)$ according to the rule as in (i), namely

$$
\tau_{1}^{*}(s) \equiv \frac{M^{*}(s)}{R_{1}}\left[\frac{1}{\beta}-1\right],
$$

we have

$$
\frac{u^{\prime}\left(c_{0}(s)\right)}{\gamma R_{1} u^{\prime}\left(c_{1}(s)\right)}-1=-\frac{u^{\prime}\left(c_{0}(s)\right)}{\gamma R_{1} u^{\prime}\left(c_{1}(s)\right)} \frac{\partial T^{b}\left(b_{1}(s)\right)}{\partial b_{1}} .
$$

Matching this with the planner optimality conditions we have

$$
\frac{\lambda}{\mu_{0} \gamma} u^{\prime}\left(c_{0}^{*}(s)\right)=-\frac{u^{\prime}\left(c_{0}^{*}(s)\right)}{\gamma R_{1} u^{\prime}\left(c_{1}^{*}(s)\right)} \frac{\left.\partial T^{b}\left(b_{1}^{*}(s)\right)\right)}{\partial b_{1}}
$$

or

$$
\frac{\lambda R_{1}}{\mu_{0}} u^{\prime}\left(c_{1}^{*}(s)\right)=-\frac{\left.\partial T^{b}\left(b_{1}^{*}(s)\right)\right)}{\partial b_{1}},
$$

where $b_{1}^{*}(s)$ is the level of bequests that implements the Mirleese allocation. If we show that in the Mirrllese allocation both $c_{1}^{*}(s)$ and $b_{1}^{*}(s)$ are increasing (or both decreasing) in $s$ then it must be that $\frac{\partial T^{b}\left(b_{1}^{*}(s)\right)}{\partial b_{1}}$ is high when $b_{1}^{*}(s)$ is high, hence the bequest tax increases with $b_{1}$, i.e., it is progressive. As we just said, we only need to show that $c_{1}^{*}(s)$ and $b_{1}^{*}(s)$ co-move in the same direction. But

$$
\begin{aligned}
& { }^{39} \text { From the Euler equation and the budget constraint, the policy of the offspring must solve } \\
& \begin{aligned}
u^{\prime}\left(c_{1}\right) & =\delta \beta R_{1}\left(1-\tau_{2}\right) u^{\prime}\left(c_{2}\right) \\
\left(R_{1}\left(1-\tau_{1}\right) b_{1}+y_{1}+T_{1}^{y}-\left(A^{*}+M^{*} b_{1}\right)\right)^{-\rho} & \Longleftrightarrow \delta \beta R_{2}\left(1-\tau_{2}\right)\left(R_{2}\left(1-\tau_{2}\right) M^{*} b_{1}+y_{2}+T_{2}^{y}\right)^{-\rho} \\
\left(R_{1}\left(1-\tau_{1}\right) b_{1}+y_{1}+T_{1}^{y}-\left(A^{*}+M^{*} b_{1}\right)\right) & \Longleftrightarrow\left(\delta \beta R_{2}\left(1-\tau_{2}\right)\right)^{-\frac{1}{\rho}}\left(R_{2}\left(1-\tau_{2}\right) M^{*} b_{1}+y_{2}+T_{2}^{y}\right),
\end{aligned}
\end{aligned}
$$

where $A^{*}$ and $M^{*}$ are the constants defining the policy and $\frac{1}{\rho}$ is the intertemporal elasticity of substitution. Since the bove relationship must hold for all $b_{1}$, taking the derivative with respect to $b_{1}$ on both sides, for all $\tau_{1}, \tau_{2}, R_{1}, R_{2}$ we have

$$
\frac{\partial b_{2}\left(\cdot ; R_{1}\left(1-\tau_{1}\right), R_{2}\left(1-\tau_{2}\right)\right)}{\partial b_{1}}\left(=M^{*}\right)=\frac{\left(1-\tau_{1}\right) R_{1}}{(\delta \beta)^{-\frac{1}{\rho}}\left(R_{2}\left(1-\tau_{2}\right)\right)^{1-\frac{1}{\rho}}+1} .
$$


this is immediate from the offspring budget constraint at the efficient allocation and taxes, and recalling that $T_{t}^{y}(s)=\tau_{t}^{*}(s) b_{t}^{*}(s)$. For all $s$ we indeed have: $c_{1}^{*}(s)+b_{2}^{*}(s)=R_{1} b_{1}^{*}(s)+y_{1}$ and $c_{2}^{*}(s)=$ $R_{2} b_{2}^{*}(s)+y_{2}$, which combined together generates 40

$$
c_{1}^{*}(s)+\frac{c_{2}^{*}(s)}{R_{2}}=y_{1}+\frac{y_{2}}{R_{2}}+R_{1} b_{1}^{*}(s) .
$$

Since, $c_{1}^{*}(s)$ and $c_{2}^{*}(s)$ are increasing in $s$ then $b_{1}^{*}(s)$ must also increase with $s$. In fact, the value of $b_{1}^{*}(s)$ is fully pinned down from this equation for all $s$. Finally, for each $s$ given $c_{0}^{*}(s), b_{1}^{*}(s), y_{0}^{*}(s)$ and $K_{0}$, we set $T_{0}^{y}(s)=c_{0}^{*}(s)+b_{1}^{*}(s)+T^{b}\left(b_{1}^{*}(s)\right)-R_{0} K_{0}-y_{0}^{*}(s)$. As argued above, since agents will choose this allocation for each declaration $\sigma=s$ no matter what is their true level of skills, incentive compatibility implies the parent will always tell the truth.

As it is clear from equation 50 in the footnote, since $1-\tau_{2}^{*}(s)$ increases with $s$, for $\rho>1$, both $\frac{M^{*}(s)}{1-\tau_{1}^{*}(s}$ and $\tau_{1}^{*}(s)$ increases with $s$ as well. In equation 51 indeed, we can write it as

$$
\frac{\tau_{1}^{*}(s)}{1-\tau_{1}^{*}(s)}=\frac{R_{1}}{(\delta \beta)^{-\frac{1}{\rho}}\left(R_{2}\left(1-\tau_{2}^{*}(s)\right)\right)^{1-\frac{1}{\rho}}+1} .
$$

More precisely, when $\rho \geq 1$ an alternative implementation of the efficient allocation involves a new $\hat{T}^{b}(\cdot), \hat{\tau}_{1}(s) \equiv 1$, we keep $\hat{\tau}_{2}(s)=\tau_{2}^{*}(s)$, and the new optimal bequest tax function $\hat{T}^{b}(\cdot)$ is convex. Note that for $\log$ utility $\tau_{1}^{*}(s)$ will be in any case state independent.

\section{A.8 Derivation of the Optimality Condition for Illiquid Bequests}

The first-order condition for illiquid bequests is given by

$$
\left(b_{t+2}^{o}\right): u^{\prime}\left(c_{t}^{o}\right)=\gamma \delta\left(\begin{array}{c}
u^{\prime}\left(c_{t+1}\right)\left[-\frac{d b_{t+2}}{d b_{t+2}^{o}}\right]+\delta u^{\prime}\left(c_{t+2}\right)\left[R_{t+2} \frac{d b_{t+2}}{d b_{t+2}^{o}}+R_{t+1} R_{t+2}-\frac{d b_{t+3}}{d b_{t+2}^{o}}\right] \\
+\sum_{i=3}^{I-1} \delta^{i-1} u^{\prime}\left(c_{t+i}\right) \frac{\partial c_{t+i}}{\partial b_{t+2}^{o}}+\delta^{I-1} V_{1}\left(a_{t+I}, Q_{t+I}\right) R_{t+I} \frac{\partial b_{t+1}}{\partial b_{t+2}^{o}}
\end{array}\right) .
$$

Observe that a change in illiquid bequests affects $b_{t+3}$ both directly and indirectly through its effect on $b_{t+2}$ :

$$
\frac{d b_{t+3}}{d b_{t+2}^{o}}=\frac{\partial b_{t+3}}{\partial b_{t+2}^{o}}+\frac{\partial b_{t+3}}{\partial b_{t+2}} \frac{d b_{t+2}}{d b_{t+2}^{o}}
$$

Now, plugging (52) into the parent's first-order condition for illiquid bequests and rearranging, we get

$$
u^{\prime}\left(c_{t}^{o}\right)=\gamma\left(R_{t+1} R_{t+2} \delta^{2} u^{\prime}\left(c_{t+2}\right)+\frac{\partial b_{t+2}}{\partial b_{t+2}^{o}} \Delta_{t+1}+\frac{\partial b_{t+3}}{\partial b_{t+2}^{o}} \Delta_{t+2}\right),
$$

\footnotetext{
${ }^{40}$ Note that this net of taxes discounting only occurs at the efficient allocation, in other terms, this is not a definition of the budget constraint. As described above, the offsprings perceives a different (subsidized) discounting of future income and consumption.
} 
where

$$
\begin{aligned}
& \Delta_{t+1}=\left[-u^{\prime}\left(c_{t+1}\right)+\delta\left(\sum_{i=2}^{I-1} \delta^{i-2} u^{\prime}\left(c_{t+i}\right) \frac{\partial c_{t+i}}{\partial b_{t+2}}+\delta^{I-2} V_{1}\left(a_{t+I}, Q_{t+I}\right) R_{t+I} \frac{\partial b_{t+I}}{\partial b_{t+2}}\right)\right], \\
& \Delta_{t+2}=\left[-u^{\prime}\left(c_{t+2}\right)+\delta\left(\sum_{i=3}^{I} \delta^{i-3} u^{\prime}\left(c_{t+i}\right) \frac{\partial c_{t+i}}{\partial b_{t+3}}+\delta^{I-3} V_{1}\left(a_{t+I}, Q_{t+I}\right) R_{t+I} \frac{\partial b_{t+I}}{\partial b_{t+3}}\right)\right] .
\end{aligned}
$$

Using (35) in (54) and the offspring's optimality condition for period $t+2$ savings, (36), in (55), we get

$$
\begin{aligned}
\Delta_{t+1} & =0, \\
\Delta_{t+2} & =\delta u^{\prime}\left(c_{t+2}\right)\left[-1+\frac{1}{\beta_{3}}\right] .
\end{aligned}
$$

Pluggin these back into (53), we reach equation (37) in the text. 